Article

\title{
Single-Ion Magnet and Photoluminescence Properties of Lanthanide(III) Coordination Polymers Based on Pyrimidine-4,6-Dicarboxylate
}

\author{
Oier Pajuelo-Corral 1 ${ }^{\complement}$, Jose Angel García ${ }^{2}$, Oscar Castillo ${ }^{3,4}$, Antonio Luque ${ }^{3,4}$, Antonio Rodríguez-Diéguez ${ }^{5}$ \\ and Javier Cepeda ${ }^{1, *(1)}$ \\ 1 Departamento de Química Aplicada, Facultad de Química, Universidad del País Vasco/Euskal Herriko \\ Unibertsitatea (UPV/EHU), 20018 Donostia, Spain; oier.pajuelo@ehu.eus \\ 2 Departamento de Física Aplicada II, Facultad de Ciencia y Tecnología, Universidad del País Vasco/Euskal \\ Herriko Unibertsitatea (UPV/EHU), 48940 Leioa, Spain; joseangel.garcia@ehu.eus \\ 3 Departamento de Química Inorgánica, Facultad de Ciencia y Tecnología, Universidad del País Vasco/Euskal \\ Herriko Unibertsitatea (UPV/EHU), 48940 Leioa, Spain; oscar.castillo@ehu.eus (O.C.); \\ antonio.luque@ehu.eus (A.L.) \\ 4 BCMaterials, Basque Center for Materials, Applications and Nanostructures, UPV/EHU Science Park, \\ 48940 Leioa, Spain \\ 5 Departamento de Química Inorgánica, Facultad de Ciencias, Universidad de Granada, 18071 Granada, Spain; \\ antonio5@ugr.es \\ * Correspondence: javier.cepeda@ehu.es; Tel.: +34-943015409
}

check for

updates

Citation: Pajuelo-Corral, O.; García,

J.A.; Castillo, O.; Luque, A.;

Rodríguez-Diéguez, A.; Cepeda, J.

Single-Ion Magnet and

Photoluminescence Properties of

Lanthanide(III) Coordination

Polymers Based on

Pyrimidine-4,6-Dicarboxylate.

Magnetochemistry 2021, 7, 8 .

https://doi.org/10.3390/

magnetochemistry7010008

Received: 4 December 2020

Accepted: 29 December 2020

Published: 4 January 2021

Publisher's Note: MDPI stays neutral with regard to jurisdictional clai$\mathrm{ms}$ in published maps and institutional affiliations.

Copyright: $\odot 2021$ by the authors. Licensee MDPI, Basel, Switzerland. This article is an open access article distributed under the terms and conditions of the Creative Commons Attribution (CC BY) license (https:// creativecommons.org/licenses/by/ $4.0 /)$.
Abstract: Herein, we report the magnetic and photoluminescence characterization of coordination polymers (CP) built from the combination of lanthanide(III) ions, pyrimidine-4,6-dicarboxylate (pmdc) ligand and a co-ligand with formula $\left\{\left[\mathrm{Dy}(\mu-\mathrm{pmdc})(\mu-\mathrm{ox})_{0.5}\left(\mathrm{H}_{2} \mathrm{O}\right)_{3}\right] \cdot 2 \mathrm{H}_{2} \mathrm{O}\right\}_{\mathrm{n}}(\mathbf{1}-\mathrm{Dy}),\left\{\left[\mathrm{Dy}\left(\mu_{3}-\right.\right.\right.$ pmdc $\left.\left.)(\mu-\mathrm{ox})_{0.5}\left(\mathrm{H}_{2} \mathrm{O}\right)_{2}\right] \sim 2.33 \mathrm{H}_{2} \mathrm{O}\right\}_{\mathrm{n}}(2-\mathrm{Dy}),\left\{\left[\mathrm{Dy}_{2}\left(\mu_{3} \text {-pmdc }\right)\left(\mu_{4} \text {-pmdc }\right)(\mu-\mathrm{ox})\left(\mathrm{H}_{2} \mathrm{O}\right)_{3}\right] \cdot 5 \mathrm{H}_{2} \mathrm{O}\right\}_{\mathrm{n}}(3-\mathrm{Dy})$, $\left\{\left[\mathrm{Ln}\left(\mu_{3} \text {-pmdc) }(\mu \text {-ox })_{0.5}\left(\mathrm{H}_{2} \mathrm{O}\right)_{2}\right] \cdot \mathrm{H}_{2} \mathrm{O}\right\}_{n}(\right.$ where $\mathrm{Ln}(\mathrm{III})=\mathrm{Nd}(4-\mathrm{Nd}), \mathrm{Sm}(4-\mathrm{Sm}), \mathrm{Eu}(4-\mathrm{Eu})$ and Dy (4-Dy) $)$ and $\left\{\left[\mathrm{Dy}\left(\mu_{4} \text {-pmdc }\right)\left(\mathrm{NO}_{3}\right)\left(\mathrm{H}_{2} \mathrm{O}\right)\right] \cdot \mathrm{H}_{2} \mathrm{O}\right\}_{\mathrm{n}}$ (5-Dy). It must be noted the presence of oxalate anion acting as ditopic co-ligand in compounds 1-Dy, 2-Dy, 3-Dy and 4-Ln, whereas in 5-Dy the nitrate anion plays the role of terminal co-ligand. Direct current measurements carried out for the dysprosium-based CPs reveal almost negligible interactions between $\mathrm{Dy}^{3+}$ ions within the crystal structure, which is confirmed by computed values of the exchange parameters J. In addition, alternating current measurements show field-induced single-molecule magnet (SMM) behavior in compounds 1-Dy, 2-Dy, 4-Dy and 5-Dy, whereas slight-frequency dependence is also observed in 3-Dy. Solid state emission spectra performed at room temperature for those compounds emitting in visible region confirm the occurrence of significant ligand-to-lanthanide charge transfer in view of the strong characteristic emissions for all lanthanide ions. Emission decay curves were also recorded to estimate the emission lifetimes for the reported compounds, in addition to the absolute quantum yields. Among them, the high quantum yield of $25.0 \%$ measured for 4 -Eu is to be highlighted as a representative example of the good emissive properties of the materials.

Keywords: single-molecule magnets; lanthanide(III) ions; coordination polymers; slow relaxation of the magnetization; photoluminescence

\section{Introduction}

The pre-designed synthesis and characterization of coordination polymers (CPs) has clearly become a primary research strategy in order to yield a particular multifunctional material which exhibits good performance in a particular research field by combining multiple physical properties [1,2]. A main reason is derived from the fact that these materials may be oriented to a particular spatial arrangement and topology which better fits the desired property, usually achieved by selecting the appropriate metal ions and organic ligands among 
an almost infinite bench of combinations [3,4]. In fact, the actual research on these materials is mainly focused on their more classical properties, including adsorption/purification of pollutant or fuel gases [5-9], liquids [10], or drugs, biomolecules delivery in a controlled way $[11,12]$, catalysis $[9,13]$, magnetism $[14-16]$ and luminescence $[17,18]$, although very recently it has been also expanding to other yet unexplored novel areas such as molecular sensing [19,20], enantiospecific resolution [21] and spintronics [22]. Among all these interesting properties, magnetism and luminescence have gained an increasing interest due to the potential of CPs to behave as single-molecule magnets (SMMs) [23-26] and solids-state lighting materials (organic light-emitting diodes, OLEDs) [27], by taking advantage of previous properties, respectively. Inside this sorts of materials, those built up from the coordination of organic ligands to lanthanide(III) ions have shown enormous potential during the last years owing to their particular electronic structure, which being hardly disturbed by the ligand field in the crystal structure, affords the aforementioned properties to the resulting CP [28-31].

To start with their magnetic properties, once it was corroborated in 2014 by MínguezEspallargas et al. with a Ln(III)-based MOF (metal-organic framework) presented SMM behavior [32], the research about the way the magnetic anisotropy is manifested in the MOF's structure was studied in depth in the following years [23]. As is known, SMMs exhibit slow relaxation of the magnetization (SRM) below certain temperature (called blocking temperature, $T B$ ) as a consequence of the concurrence of large spin state in the molecule and magnetic anisotropy (usually axial, $D$; though other distributions such as plane anisotropy are also known, E). Paramagnetic lanthanide(III) ions usually present a large magnetic moment and sizeable single-ion anisotropy derived from spin-orbit coupling (soc) effect $[29,33]$ that varies according to nature and symmetry of their local environment, in such a way that they may lead to astonishing energy barriers which impede the reversal of the magnetization in the compound [34]. On another level, the use of these metal centers is often compatible with the occurrence of luminescence on the CPs, given $\mathrm{f}-\mathrm{f}$ based intraionic emissions can occur in lanthanide-organic frameworks (Ln-OFs) provided that inner levels of lanthanides(III) keep undistorted by the molecular ligand-based electronic structure [35,36]. Moreover, although the light-absorbing capacity of these metal ions is quite low due to their narrow absorption bands (despite the high intensity of many bands in the ultraviolet (UV) region), their coordination to organic ligands may largely improve this problem by means of the antennae effect, by which the energy absorbed by the ligand is transferred from its excited triplet state to an excited Ln(III)-based inner state from which the emissive state is eventually populated $[37,38]$.

Bearing these ideas in mind, together with the fact that Ln-OFs require the use of ligands that are able to not only isolate lanthanide(III) centers from each other in the network to bring SRM but also provide both good light absorption and effective transfers to the lanthanide(III), we have turned to pyrimidine-4,6-dicarboxylate (pmdc) [39]. As previously proved by our group $[40,41]$, this ligand fulfills both requisites by presenting low capacity to set magnetic exchange interactions among lanthanide(III) centers while it brings good absorption capacity. Therefore, in this study we undertake a detailed analysis of the single-ion magnet and photoluminescent properties of Ln-pmdc based compounds to evaluate their potential in the field of magneto-luminescent functional materials.

\section{Results and Discussion}

\subsection{Brief Structural Overview}

There are five different crystalline families of coordination polymers described in this work, which consist of lanthanide(III) ions, pmdc ligand and a co-ligand that changes for a particular family. In particular, the co-ligand is oxalate for compounds 1-Dy, 2-Dy, 3-Dy and 4-Ln because it is in situ generated in the reaction media (as part of a well-known ringopening concomitant reaction that happens in aqueous mixtures containing lanthanide(III) ions in acidic $\mathrm{pH}$ and open atmosphere, observed not only for pmdc ligand but also for many other similar aromatic molecules) [42] and thus incorporated to the final products. 
Despite the fact that oxalate ligand shares a unique coordination pattern in all compounds (the most habitual bis-bidentate mode as expected for its large affinity to lanthanide(III) ions according to the Hard-Soft Acid-Base (HSAB) principle) [43], pmdc ligand shows a variable coordination flexibility that depends on the entropy driven desolvation pathway $[44,45]$. In this sense, lanthanide(III) ions coordinate to less water molecules as the temperature of hydrothermal reaction rises, in such a way that the vacant positions in the coordination shell are more easily occupied by carboxylate oxygen atoms belonging to the pmdc ligand. Hence, pmdc ligand increases its denticity moving from the basal bis-chelating mode $\left(\mu-\kappa^{2} N, O: \kappa^{2} N^{\prime}, O^{\prime}\right)$ in 1-Dy to other highly coordinating modes $\left(\mu_{3}-\kappa^{2} N, O: \kappa^{2} N^{\prime}, O^{\prime}: k O^{\prime \prime}\right.$ in 2-Dy, 3-Dy and 4-Ln and $\mu_{4}-\kappa^{2} N, O: \kappa^{2} N^{\prime}, O^{\prime}: \kappa O^{\prime \prime}: \kappa O^{\prime \prime \prime}$ in 5-Dy) as the temperature rises. The aforementioned effect is also noticed by the presence of less water molecules (including coordination and crystallization molecules) per lanthanide(III) atom enclosed in the crystal packings of the CPs, which eventually generates more condensed frameworks (1-Dy $<\mathbf{2}-\mathrm{Dy}$ $<3-\mathrm{Dy}<4$-Ln) with the increasing synthesis temperature. It is worth highlighting that all these coordination modes share the occurrence of two N/O-chelating rings, a fact that forces the ligand to acquire a planar arrangement. In fact, this may be taken as a characteristic fact of pmdc ligand because such preponderant coordination mode is only prevented when a bulky substituent is present in the ligand such as the phenyl ring in ppmdc (2-phenylpyrimidine-4,6-dicarboxylic acid), in which the coordination through the nitrogen atoms is hindered in the $\mathrm{CP}$ of $\left\{\left[\mathrm{Eu}(\mathrm{ppmdc})(\mathrm{phen})\left(\mathrm{C}_{2} \mathrm{O}_{4}\right)_{0.5}\right] \cdot 0.5 \mathrm{H}_{2} \mathrm{O}\right\}_{\mathrm{n}}$ formula [46].

On the other hand, compound 5-Dy possesses nitrate anions as co-ligand due to the solvent-free procedure employed for its synthesis. In this case, the reagents (dysprosium(III) nitrate hydrate and $\mathrm{H}_{2}$ pmdc) are directly mixed and heated at $190{ }^{\circ} \mathrm{C}$ in a closed vessel, such that the melt formed is very rich in nitrate ions and yield single crystals in which those anions are able to compete with water molecules for occupying coordination sites.

Apart from the structures included in this work, it must be mentioned that pmdc ligand is able to render some additional crystalline compounds with most of lanthanide ions involving no additional linkers, namely $\left\{\left[\mathrm{Ln}(\mu-\mathrm{pmdc})_{1.5}\left(\mathrm{H}_{2} \mathrm{O}\right)_{3}\right] \cdot \mathrm{xH}_{2} \mathrm{O}\right\}_{\mathrm{n}}$ (where $\mathrm{x}=5.5-6.5$ depending on the metal ion) and $\left\{\left[\mathrm{Ln}_{2}\left(\mu_{4} \text {-pmdc }\right)_{2}(\mu-\mathrm{pmdc})\left(\mathrm{H}_{2} \mathrm{O}\right)_{2}\right] \cdot \mathrm{H}_{2} \mathrm{O}\right\}_{n} \mathrm{CPs}$ [47], in addition to the MOF of $\left\{\left[\mathrm{Eu}\left(\mu_{4}-\mathrm{pmdc}\right)_{2}\left(\mu_{3}-\mathrm{OH}\right)_{2}\right] \cdot 3 \mathrm{H}_{2} \mathrm{O}\right\}_{\mathrm{n}}$ formula [48] in which hydroxide anion acts a co-ligand. In both cases, the compounds are synthesized starting from aqueous solutions with basic $\mathrm{pH}$ under solvothermal conditions, a medium that avoids the aforementioned spontaneous generation of oxalate [42] in such a way that these alternative frameworks are crystallized.

\subsection{Structural Description}

A detailed structural description of most of the compounds, except for compounds 4-Ln (whose crystallographic data are summarized in Table S1), has been already done in previously reported works $[40,41]$, so their structural description will be briefly discussed. Compound 1-Dy crystallizes in the monoclinic $P 2_{1} / n$ space group with $\{[\mathrm{Dy}(\mu-\mathrm{pmdc})$ $\left.\left.(\mu \text {-ox })_{0.5}\left(\mathrm{H}_{2} \mathrm{O}\right)_{3}\right] \cdot 2 \mathrm{H}_{2} \mathrm{O}\right\}_{n}$ formula as part of a family of other isostructural homologues with other lanthanide(III) ions. The Dy atom is linked to two pmdc ligands, one oxalate anion and three water molecules, rendering a nine-coordinated $\mathrm{N}_{2} \mathrm{O}_{4} \mathrm{Ow}_{3}$ donor set which can be described as a spherical capped square antiprism (CSAPR) polyhedron ( $\mathrm{S}_{\mathrm{CSAPR}}=0.806$, see Supporting information, Table S2) as depicted by the continuous shape measurements (CShMs) using the SHAPE program [49]. The coordination bonds are in the range of

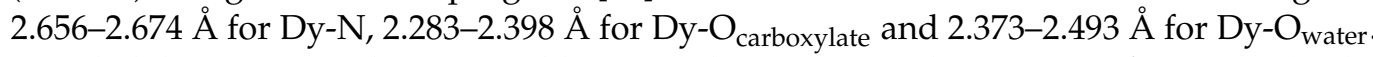
Detailed distances are shown in Table S3 on Electronic Supplementary Information (ESI).

The metal centers are linked by planar bis-bidentate pmdc ligands into a corrugated chain along the crystallographic $b$ axis, in which an intermetallic distance of ca. $7.24 \AA$ is imposed. Moreover, the adjacent chains are joined to one another by the bis-chelating oxalate anion, which separates the dysprosium atoms at ca. $6.14 \AA$ and gives rise to 2D sheets of hcb topology that spread along the (101) plane. The successive planes are connected into the 3D packing by means of hydrogen bonds established between the 
coordinated water molecules and uncoordinated oxygen atoms of pmdc ligands belonging to adjacent sheets (Figure 1). Moreover, lattice water molecules placed between sheets take part into additional hydrogen bonding interactions with the 2D metal-organic sheets, which reinforces the overall crystal structure. For comparative purposes, this framework resembles the isoreticular architecture shown by the oxalate-free compound of $\{[\mathrm{Dy}(\mu-$ pmdc $\left.\left.)_{1.5}\left(\mathrm{H}_{2} \mathrm{O}\right)_{3}\right] \cdot 5.5 \mathrm{H}_{2} \mathrm{O}\right\}_{\mathrm{n}}$ formula in which the oxalate bridge is replaced by an additional bis-chelating pmdc linker yields a similar 2D-layered structure [47]. In fact, the most significant change of 1-Dy with respect to $\left\{\left[\mathrm{Dy}(\mu \text {-pmdc })_{1.5}\left(\mathrm{H}_{2} \mathrm{O}\right)_{3}\right] \cdot 5.5 \mathrm{H}_{2} \mathrm{O}\right\}_{\mathrm{n}}$ is the slight change occurring in the network as result of replacement a $\mu$-ox by a $\mu$-pmdc, with the subsequent enlargement in the Dy...Dy distance of ca. $1 \AA$ (from ca. 6.1 to $7.3 \AA$ ).

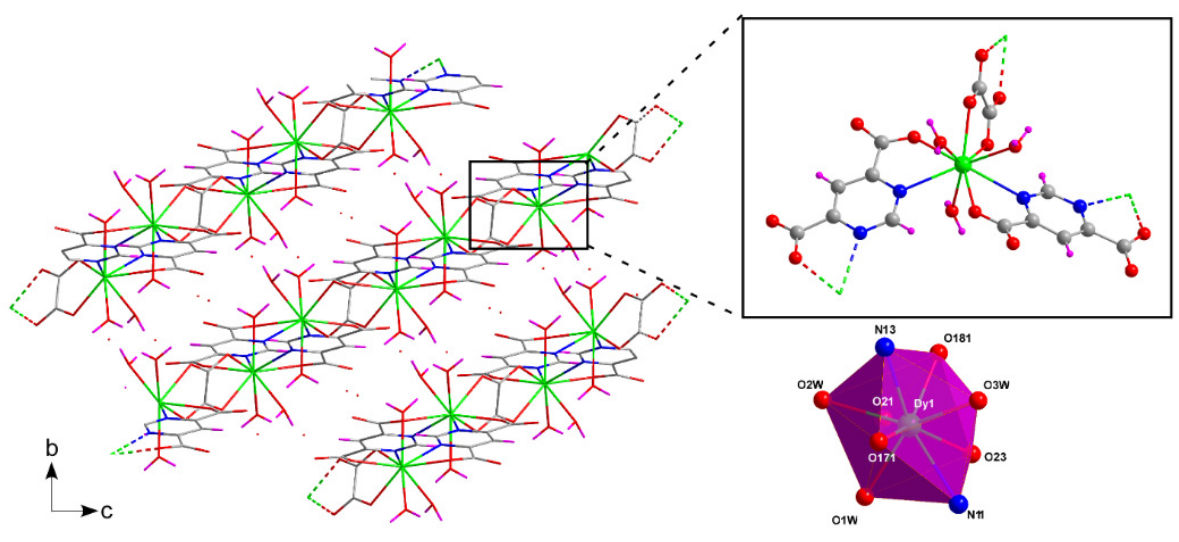

Figure 1. Crystal packing of 1-Dy showing the $2 \mathrm{D}$ sheets. Inset represents a fragment of the compound with the coordination polyhedron. Color coding: green, dysprosium; red, oxygen; blue, nitrogen; grey, carbon; pink, hydrogen.

Being crystallized in the $P 2_{1} / n$ space group, the titled compound 2-Dy presents the $\left\{\left[\mathrm{Dy}\left(\mu_{3} \text {-pmdc }\right)(\mu \text {-ox })_{0.5}\left(\mathrm{H}_{2} \mathrm{O}\right)_{2}\right] \sim 2.33 \mathrm{H}_{2} \mathrm{O}\right\}_{\mathrm{n}}$ formula and shows a similar structure to that of 1-Dy, but with one of the coordinated water molecules being replaced by a non-chelating oxygen atom of the pmdc ligand (which was uncoordinated in 1-Dy), a fact that increases the dimensionality of the structure to give rise to a 3D framework. Hence, in the core of the building crystal, the dysprosium atom shows a $\mathrm{N}_{2} \mathrm{O}_{5} \mathrm{Ow}_{2}$ donor set coming from two symmetrically related pmdc ligands, a centrosymmetric oxalate anion and two coordinated water molecules (Figure 2). Distances between dysprosium and donor atoms in the coordination center are listed in Table S3. This replacement in the coordination sphere increases the distortion of the coordination polyhedron with regard to the previously analyzed ideal geometry, in such a way that the environment of Dy1 atom in 2-Dy corresponds to an intermediate between CSAPR and spherical tricapped trigonal prism (TCTPR) as shown by the CShMs $\left(S_{\text {CSAPR }}=0.828\right.$ and $S_{\text {TCTPR }}=0.738$, Table S2). Despite the similar connection shown for 1-Dy, the rearrangement of the coordination sphere promotes some distance changes between metal centers (Dy...Dy distance is $7.03 \AA$ between for pmdc bridging centers and $6.23 \AA$ for oxalate bridging centers, respectively). Moreover, the $\mu_{3}-\mathrm{KN}, \mathrm{O}: \mathrm{KN}^{\prime}, \mathrm{O}^{\prime}: \mathrm{KO}^{\prime \prime}$ coordination mode displayed by the pmdc ligand in 2-Dy yields an open 3D framework of ins topology (it is a bimodal network because not only lanthanide but also the pmdc ligand act as nodes). Solvent water molecules are placed in the channels of the architecture by bringing irregular patterns owing to the crystallographic modulation (the structure is more precisely described as a $1 \times 1 \times 3$ supercell) existing in the structure which, in any case, does not affect the already described overall crystal architecture (Figure 2).

Compound 3-Dy, obtained as a polycrystalline powder, corresponds to a family of isostructural CPs of $\left\{\left[\mathrm{Ln}_{2}\left(\mu_{3} \text {-pmdc }\right)\left(\mu_{4} \text {-pmdc }\right)(\mu \text {-ox })\left(\mathrm{H}_{2} \mathrm{O}\right)_{3}\right] \cdot 5 \mathrm{H}_{2} \mathrm{O}\right\}_{\mathrm{n}}$ formula (Figure S1). These compounds crystallize in the non-centrosymmetric $P n a 2_{1}$ space group and show a crystal structure related to that of 2-Dy because it also exhibits a 3D open framework. However, in 3-Dy there are two crystallographic independent metal centers, one of which 
(Ln1) shows the previously specified $\mathrm{LnN}_{2} \mathrm{O}_{5} \mathrm{Ow}_{2}$ coordination environment, whereas in the second center ( $\mathrm{Ln} 2)$ one of the coordinated water molecules is replaced by an oxygen of pmdc ligand, thus displaying a $\mathrm{LnN}_{2} \mathrm{O}_{6} \mathrm{Ow}$ coordination environment (Figure 3). Despite the fact that no further details on the coordination environment can be given for the dysprosium counterpart, based on the Gd analogue, it may be concluded that the larger connectivity afforded by pmdc brings an increased distortion in the metal center ( $\mathrm{S}_{\text {TCTPR }}$ $=1.074$ and $\mathrm{S}_{\mathrm{CSAPR}}=0.587$ for Ln 1 and Ln 2, respectively). The linkage of the metal centers by the highly connected pmdc ligands gives rise to a three-dimensional architecture that possesses the jcr1 topology and exhibits tubular channels along the crystallographic $a$ axis, which are filled by lattice water molecules. Putting aside the specific topology of shown by this framework, it shares strict structural relationship with the previously reported oxalate-free $\mathrm{CP}$ of $\left\{\left[\mathrm{Dy}_{2}\left(\mu_{4} \text {-pmdc }\right)_{2}(\mu \text {-pmdc })\left(\mathrm{H}_{2} \mathrm{O}\right)_{2}\right] \cdot \mathrm{H}_{2} \mathrm{O}\right\}_{n}$ formula [47], since the latter may be considered as the next step to bring higher metal-organic connectivity in the 3D framework. In the same way as was explained for the 1-Dy $\leftrightarrow$ 2-Dy pair, the aforementioned oxalate-free $\mathrm{CP}$ may be considered the result of a subsequent replacement of a coordination water molecule by a non-chelating carboxylate oxygen atom of pmdc ligand in the architecture of 3-Dy, a fact that is only achieved in the absence of oxalate ligand, in such a way that pmdc linker can accommodate the required arrangement in the framework to increase its coordination to dysprosium(III) ions.

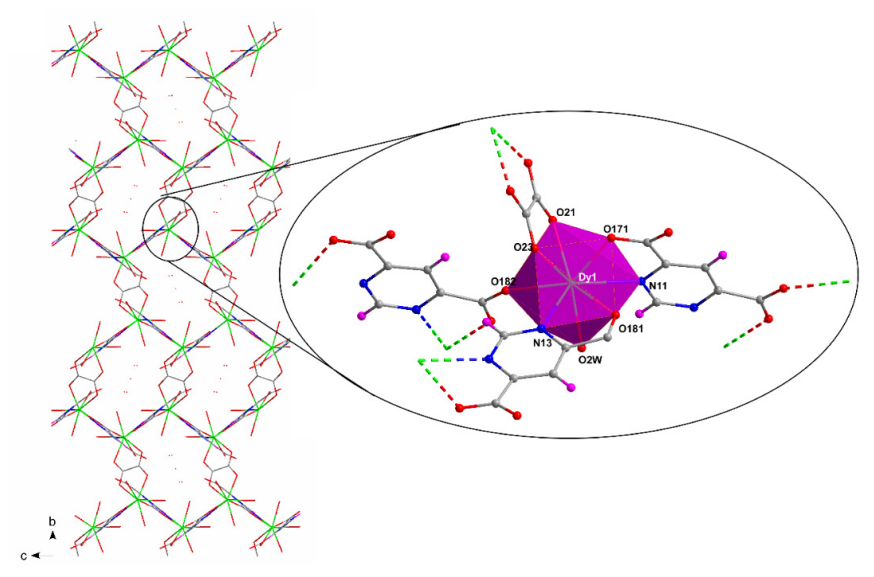

Figure 2. Crystal packing of 2-Dy showing the environment around the metal center. Color coding: green, dysprosium; red, oxygen; blue, nitrogen; grey, carbon; pink, hydrogen.
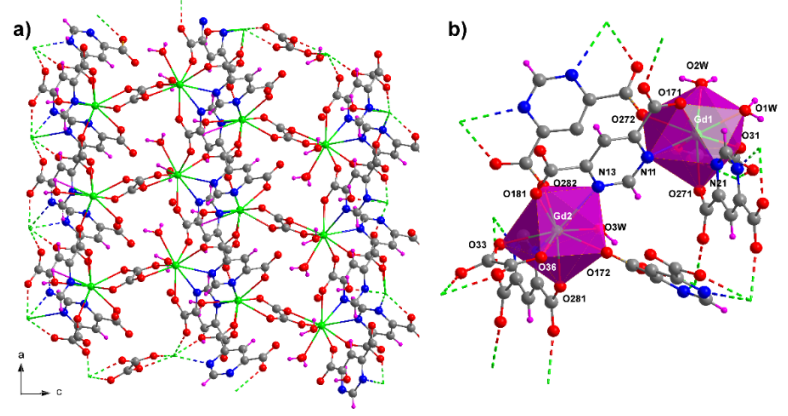

Figure 3. (a) Crystal building of the previously reported Gd-based coordination polymer (CP) isostructural to 3-Dy. (b) Fragment of compound 3-Gd showing the coordination polyhedron and the environment around the metal centers. Color coding: green, metal; red, oxygen; blue, nitrogen; grey, carbon; pink, hydrogen.

Compounds 4-Ln are all isostructural as confirmed by the single-crystal X-ray diffraction measurements for compounds 4-Nd, 4-Sm and 4-Eu and by the PXRD data analysis of a polycrystalline sample of 4-Dy (Figure S2). They crystallize in the $P 2_{1} / n$ crystallographic space group and belong to the previously reported family with $\left\{\left[\operatorname{Ln}\left(\mu_{3}-\mathrm{pmdc}\right)(\mu-\right.\right.$ 
ox $\left.\left.)_{0.5}\left(\mathrm{H}_{2} \mathrm{O}\right)_{2}\right] \cdot \mathrm{H}_{2} \mathrm{O}\right\}_{\mathrm{n}}(\mathrm{Ln}=\mathrm{La}$ and $\mathrm{Ce})$ formula [40]. The crystal structure is very similar to 2-Dy, since it shows an almost identical 3D framework of the same topological class but which differs in the number of lattice molecules, being dropped to solely one. Accordingly, there are no significant changes in the coordination sphere, which keeps the $\mathrm{LnN}_{2} \mathrm{O}_{5} \mathrm{Ow}_{2}$ chromophore that resembles CSAPR (Table S2). Further analysis of these structures reveal that their coordination shell is less distorted as the ion size of the lanthanide gets smaller, as confirmed by CShMs $\left(\mathrm{S}_{\mathrm{TCTPR}}=0.955,0.889\right.$ and 0.845 respectively for $\mathrm{Nd}^{3+}, \mathrm{Sm}^{3+}$, and $\left.\mathrm{Eu}^{3+}\right)$, although the distortion is still higher than that found for compound 1-Dy. The distances between metal centers and donor atoms are listed in Table S3. To end up with the description of these structures, it must be highlighted that the loss of the water molecules results in a contraction of the framework, which presents no continuity of accessible voids for solvent molecules (that is, channels) and, therefore, a more compacted crystal building (Figure 4).

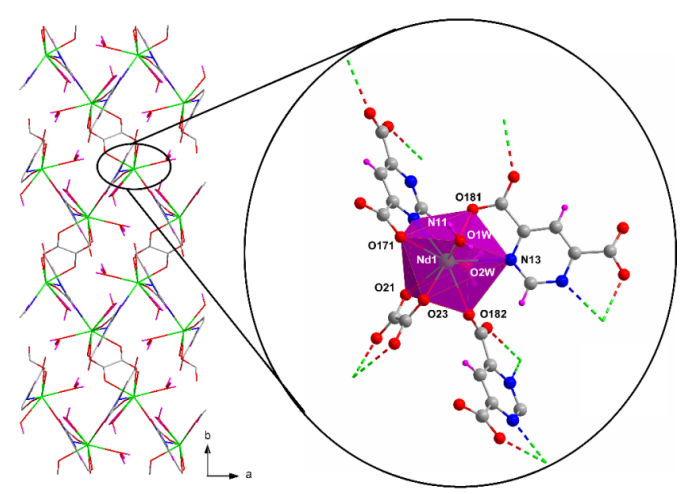

Figure 4. Packing of compound 4-Nd with a detailed illustration of the coordination sphere. Color coding: green, dysprosium; red, oxygen; blue, nitrogen; grey, carbon; pink, hydrogen.

At last, compound 5-Dy crystallizes in the hexagonal $\mathrm{P}_{3}$ space group and possesses the $\left\{\left[\mathrm{Dy}\left(\mu_{4} \text {-pmdc }\right)\left(\mathrm{NO}_{3}\right)\left(\mathrm{H}_{2} \mathrm{O}\right)\right] \cdot \mathrm{H}_{2} \mathrm{O}\right\}_{\mathrm{n}}$ formula. In this case, the coordination around the central lanthanide(III) atom is completed by the $\mathrm{N}_{2} \mathrm{O}_{6} \mathrm{Ow}$ donor set, which is formed by two N/O-chelating pmdc ligands, two O-terminal pmdc ligands, a chelating nitrate anion and a water molecule. The resulting polyhedron resembles a muffin $\left(\mathrm{S}_{\mathrm{MFF}}=0.410\right.$, see Table S2), which can be considered as a less symmetric shape. Note that the calculated geometry was obtained for the Gd-analogue [41], whose geometry is not expected to be significantly different from compound 5-Dy. The presence of the nitrate anion in the coordination shell, compared to the oxalate, drops the connectivity of the co-ligand, though this fact is taken as an advantage by pmdc ligand because it links to four metal centers by acquiring the $\mu_{4}-\mathrm{KN}, \mathrm{O}: \mathrm{KN}^{\prime}, \mathrm{O}^{\prime}: \mathrm{KO}^{\prime \prime}: \mathrm{KO}^{\prime \prime \prime}$ coordination mode previously seen in compound 3-Dy. Hence, pmdc ligands bridge dysprosium ions one another by building a kind of triangle-shaped building units which are further linked into the resulting 3D framework that belongs to the ssa topology. The architecture possesses tubular channels occupied by lattice water molecules (Figure 5).

a)

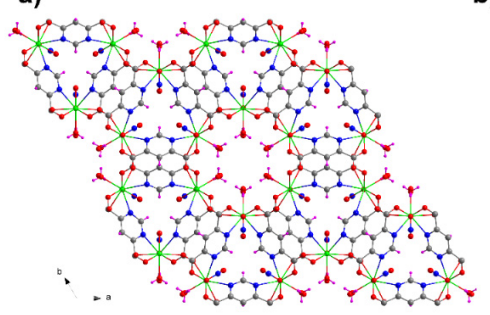

b)

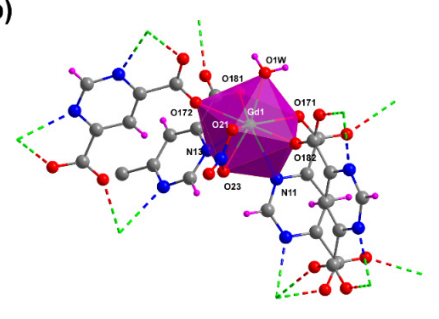

Figure 5. (a) Packing of reported isostructural 5-Gd showing the tubular channels along c axes. (b) Fragment of 5-Gd showing the coordination environment. Color coding: green, metal; red, oxygen; blue, nitrogen; grey, carbon; pink, hydrogen 


\subsection{Static Magnetic Properties}

The analysis of the variable-temperature evolution of the molar magnetic susceptibility $\left(\chi_{M}\right)$ of the dysprosium-based counterparts, previously measured and reproduced here (Figure 6) [40,41], indicates that these compounds present a usual magnetic behavior dominated by the spin-orbit coupling (soc) of the paramagnetic ions. According to this, the $\chi_{M} T$ product at room temperature per one dysprosium(III) atom is ca. $14 \mathrm{~cm}^{3} \mathrm{~K} \mathrm{~mol}^{-1}$, close to the expected one for an isolated Dy(III) with a $g_{J}$ of 1.25. All curves describe a similar shape by which the $\chi_{M} T$ product shows a slight and progressive drop cooling down from room temperature down to $50 \mathrm{~K}$, below which it describes a subtle drop to reach a value of ca. $10.3 \mathrm{~cm}^{3} \mathrm{~K} \mathrm{~mol}^{-1}$. Although a priori this kind of shape could be also attributed to the presence of antiferromagnetic exchange interactions, all compounds can be considered practically paramagnetic in view of the rectilinear drop of the $\chi_{M}{ }^{-1}$ vs $T$ plot, which gives values for the Weiss constant of nearly zero ( $\theta$ about -3.0 and -4.0 for all compounds).
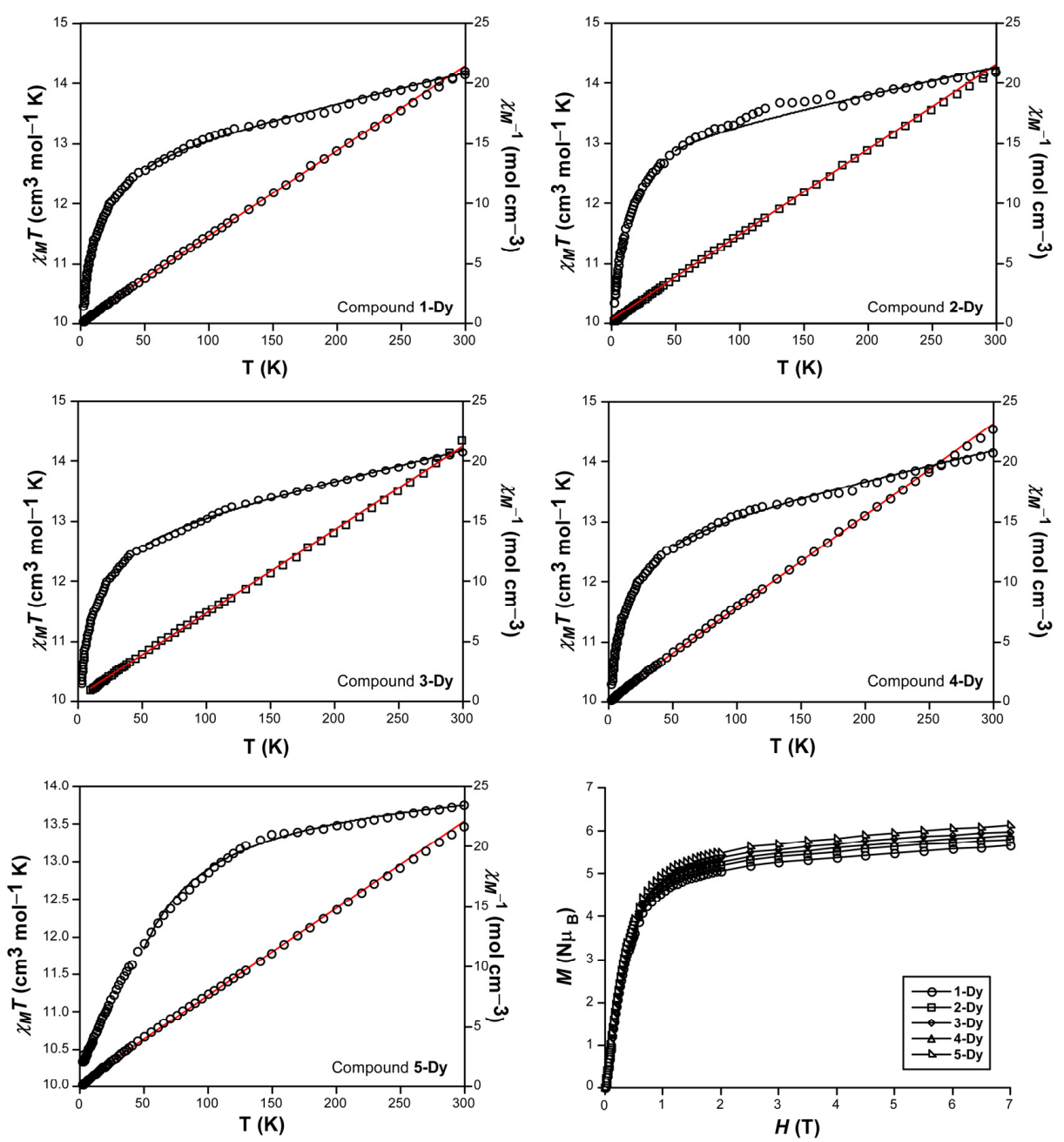

Figure 6. $\chi_{M} T$ vs $T$ and $\chi_{M}{ }^{-1}$ vs $T$ plots for all dysprosium-based compounds. The plot sited at the bottom on the right-hand side shows the isothermal $(2 \mathrm{~K})$ variable-field magnetization of the compounds.

In any case, to gain deeper insights, the Density-Functional Theory-(DFT) computed values of the coupling constant, performed on an isostructural Gd(III)-based model in which all the possible superexchange pathways present in these compounds have been also analyzed [(i) through $O, O^{\prime} / O^{\prime \prime}, O^{\prime \prime \prime}$-bis-chelating ox ligand, (ii) through $N, O / N^{\prime}, O^{\prime}$ bis-chelating pmdc ligand, (iii) through $\mathrm{N}, \mathrm{O} / \mathrm{O}^{\prime}$-mode of pmdc ligand (the short bridge 
across the same carboxylate moiety) and (iv) through $N, O / O^{\prime}$-mode of pmdc ligand (the long bridge across the other carboxylate moiety, only present in compound 3-Dy)]. Given that these calculations give very low $J$ values (Figure 7), either of positive or negative signs, we can conclude that the contribution of exchange interactions, if occurring, is practically negligible.

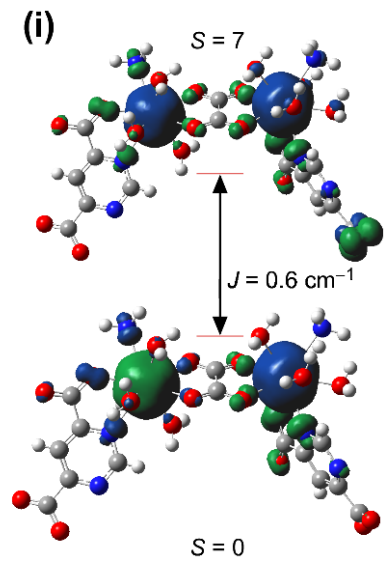

(ii)

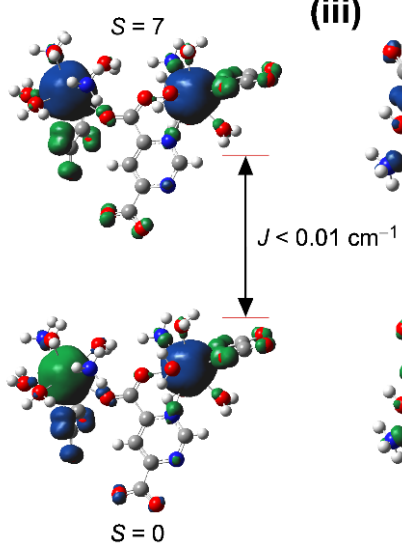

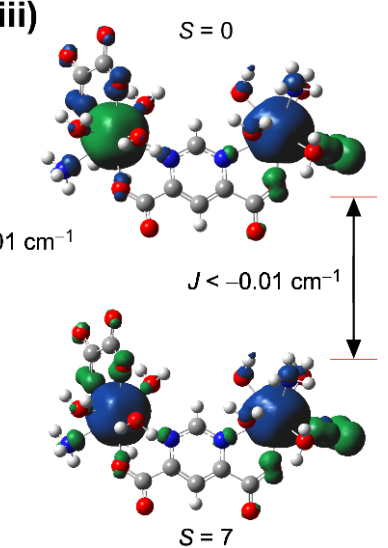

Figure 7. Spin distributions represented on the three main (i), (ii), and (iii) superexchange pathways. Note that pathway (iv) has not been shown because it involves $J=0 \mathrm{~cm}^{-1}$.

Perhaps, in the general comparison the curve of compound 5-Dy is the most remarkable one because it significantly differs from the rest in the following aspects: (i) it shows a slightly lower value of $\chi_{M} T$ at room temperature, (ii) the value of $\chi_{M} T$ remains more constant in the high temperature range (100-300 K) compared to the rest of compounds and more importantly, (iii) the drop at low temperature is not as abrupt as for previous compounds. Taking into account that Dy(III) is a Kramers ion with a ${ }^{6} \mathrm{H}_{15 / 2}$ ground term, the coordination shell can induce a different distribution of the Stark sublevels of the ion, thus influencing the magnetization resulting from the thermal depopulation occurring when lowering the temperature [50]. Therefore, such a conclusion should involve a multiconfigurational calculation on all the environments of the compounds, and the slightly higher remnant value of the magnetic susceptibility for 5-Dy could be attributed to a larger axial magnetic anisotropy in this compound compared to the oxalate-based ones. The $M(H)$ isothermal measurements carried out at $2 \mathrm{~K}$ for the compounds point indeed in the same direction, since the curve for 5-Dy exhibits a more abrupt increase and slightly larger value of magnetization compared to the rest of the compounds. These values are of ca. $6 \mathrm{~N} \mu_{\mathrm{B}}$, which is a bit lower that the expected saturation value.

\subsection{Dynamic Magnetic Properties}

In order to study the SMM behavior, alternative current $(a c)$ measurements were performed with the temperature and frequency range of $2-20 \mathrm{~K}$ and $60-10,000 \mathrm{~Hz}$ respectively, over polycrystalline samples of compounds 1-Dy, 2-Dy, 3-Dy, 4-Dy and 5-Dy in the absence and the presence of an external applied magnetic field. With no external field, none of the compounds present signal in the $\chi^{\prime \prime}$ vs. T plot, probably due to the fast relaxation through quantum tunneling of the magnetization (QTM) process. When the measurements were repeated with and external direct current $(d c)$ field of 1000 Oe in order to suppress the QTM, compounds 1-Dy, 2-Dy, 4-Dy and 5-Dy present temperature and frequency dependent maxima in the out-of-phase curves, indicating a slow relaxation of the magnetization (Figure 8). For compound 3-Dy however, there is no a significant frequency dependency of the out-of-phase signal above $2 \mathrm{~K}$ (Figure S3), which could be attributed to either the fact that the external field does not suppress the QTM or to a very small thermal energy barrier in which the maxima appear under the detection limit of the apparatus, thus impeding any further study. 


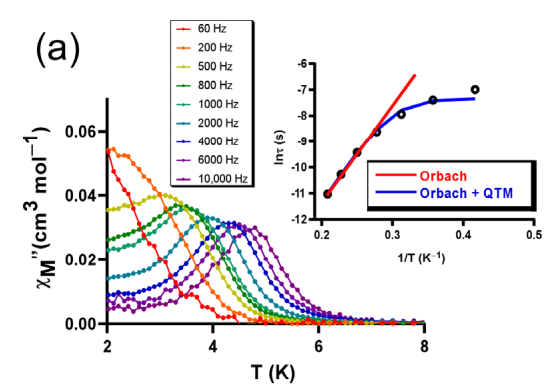

(c)

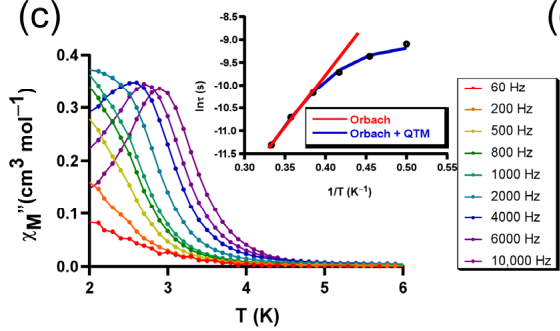

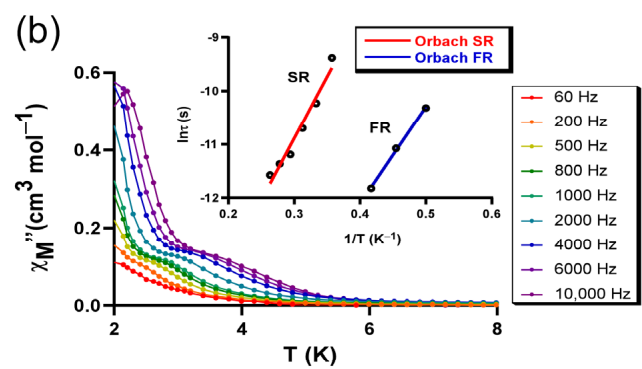

(d)

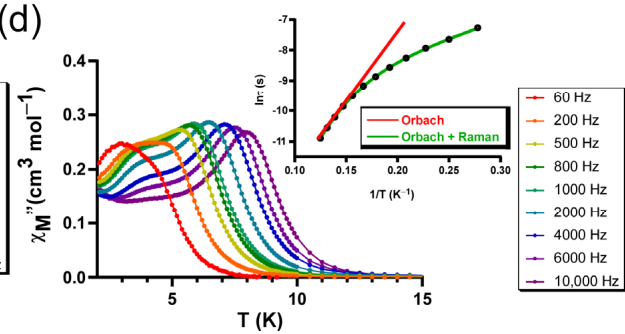

Figure 8. Temperature dependence of out-of-phase components of the ac susceptibility in a direct current $(d c)$ applied magnetic field of 1000 Oe for (a) 1-Dy, (b) 2-Dy, (c) 4-Dy and (d) 5-Dy. The insets represent the temperature dependence for the relaxation times and the best fits of the data to different relaxation processes.

When a $d c$ field of 1000 Oe is applied, compounds 1-Dy, 4-Dy and 5-Dy show frequency dependent maxima with the appearance of small shoulders at low temperatures, suggesting the QTM is still operating. The Cole-Cole plots generated for the corresponding compounds show semi-circular shapes that fit well the generalized Debye model (Figures S8 and S9), affording $\alpha$ values in the range of $0.5-0.1$. Note that $\alpha$ parameter determine the width of the different relaxation processes, meaning that $\alpha=1$ stands for infinitely wide relaxation processes whereas $\alpha=0$ indicates a narrow relaxation processes. The obtained values indicates the existence of more than one relaxation mechanism, especially in the low temperature regime. In fact, the Arrhenius plots in the form of $\ln (\tau)$ versus $1 / \mathrm{T}$ (selecting the temperature range according to the Cole-Cole plots) feature a curvilinear shape that only retains linear behavior in the high temperature region, which was fitted according to the Arrhenius law (Orbach process, in which the obtained $U_{\text {eff }}$ and $\tau_{0}$ values are represented in Table 1) [Equation (1)]. Besides the thermally activated Orbach relaxation mode, compounds 1-Dy and 4-Dy require the inclusion of the QTM process to correctly reproduce the low temperature range, whereas a combination of Orbach and Raman relaxations were employed to fit the temperature-dependent representation of the relaxation times for 5-Dy, yet the presence of QTM cannot be discarded in the low temperature region in this case. Best fits parameters (which were obtained with low errors and $\mathrm{R}^{2}$ lower than $9.0 \times 10^{-3}$ ) are listed in Table 1.

$$
\tau^{-1}=\tau_{0}^{-1} \exp \left(-\mathrm{U}_{\text {eff }} / \mathrm{k}_{\mathrm{b}} T\right)+\tau_{\mathrm{QTM}}{ }^{-1}+\mathrm{B}_{\mathrm{Raman}} T^{\mathrm{n}}
$$

Table 1. $\mathrm{U}_{\text {eff }}$ and $\tau_{0}$ values for compounds 1-Dy, 2-Dy, 4-Dy and 5-Dy.

\begin{tabular}{|c|c|c|c|c|c|c|c|c|c|}
\hline \multirow{2}{*}{ Compound } & \multicolumn{2}{|c|}{ Orbach } & \multicolumn{3}{|c|}{$\begin{array}{c}\text { Orbach + QTM (Quantum Tunneling of } \\
\text { the Magnetization) }\end{array}$} & \multicolumn{4}{|c|}{ Orbach + Raman } \\
\hline & $\mathrm{U}_{\text {eff }}(\mathrm{K})$ & $\tau_{0}(\mathrm{~s})$ & $\mathrm{U}_{\text {eff }}(\mathrm{K})$ & $\tau_{0}(\mathrm{~s})$ & $\tau_{\text {Qтм }}(\mathbf{s})$ & $\mathrm{U}_{\text {eff }}(\mathrm{K})$ & $\tau_{0}(\mathrm{~s})$ & $B_{\text {Raman }}\left(s^{-1} K^{-1}\right)$ & $\mathbf{n}$ \\
\hline 1-Dy & $35(2)$ & $1(2) \times 10^{-8}$ & $41(2)$ & $4(2) \times 10^{-9}$ & $6(4) \times 10^{-4}$ & - & - & - & - \\
\hline 2-Dy & 18(3) (FR) & $4(3) \times 10^{-9}(\mathrm{FR})$ & - & - & - & - & - & - & - \\
\hline - & 23(3) (SR) & $2(3) \times 10^{-8}(\mathrm{SR})$ & - & - & - & - & - & - & - \\
\hline 4-Dy & $22(2)$ & $8(3) \times 10^{-9}$ & $29(3)$ & $1(3) \times 10^{-9}$ & $1.1(3) \times 10^{-4}$ & - & - & - & - \\
\hline 5-Dy & $44(2)$ & $7(2) \times 10^{-8}$ & - & - & - & $70(2)$ & $5(1) \times 10^{-9}$ & $23(5)$ & $3.3(2)$ \\
\hline
\end{tabular}


In the case of compound 2-Dy, two clearly distinguishable maxima can be observed in the $\chi^{\prime \prime}$ vs. $T$ plot (Figure 8), peaking in the $2-2.6 \mathrm{~K}$ and $3-3.8 \mathrm{~K}$ temperature ranges, which may be considered as a two-step relaxation, for which they are denoted as fast (FR) and slow (SR) relaxation processes, respectively. Although the occurrence of these sorts of multiple relaxations is not completely understood and different origins have been already argued to explain it (two distinct Dy(III) ions in the network, a concomitance of singleion and extended exchange interactions, or a combination of single-ion and long-range magnetic orderings, among others) [51-53], the crystalline modulation exhibited by 2-Dy at low temperature (in which the structure possesses a commensurate order that accounts for a $1 \times 1 \times 3$ supercell) may explain the occurrence of non-equivalent relaxations in neighboring Dy(III) ions. The dual relaxation is also observed in the Cole-Cole plots in the 2.4-2.8 K region (see ESI, Figure S6, where a combination of two semicircles is appreciated. The data were fitted by using a sum of two modified Debye functions with the CCFIT software (Table S4) [54]. Once the contribution of its thermal relaxation was successfully separated, they were plotted into composed Arrhenius plots and fitted to the Orbach mechanism according to Equation (1) (Figure 8). Best fit values for the effective energy barrier of spin reversal and $\tau_{0}$ are also gathered in Table 1 . According to the extracted $\alpha$ values for the SR process, it may be surmised that more than one mechanism is involved. However, a reliable fit could not be obtained by considering multiple mechanisms.

It is widely known that the SMM behavior is strongly dependent on the coordination environment [55]. Moreover, the non spherical orbitals shape of lanthanides requires specific coordination sites in order to reduce or minimize electrostatic repulsions and stabilize the ligand field. In this way, the oblate Dy(III) ion requires the coordination of the ligands in axial positions instead of the equatorial positions to achieve high performance SMM [56]. Herein, all the studied compounds can be regarded as spherical capped square antiprism polyhedra, which possess donor atoms in both equatorial and axial positions. Thus, the reported compounds are far away from the ideal geometries of Dy(III) for achieving high energy barriers and therefore, the absence of SMM behavior at zero $d c$ field is not unexpected. Looking at the geometry of the coordination sphere and the obtained energy barriers for compounds 1-Dy, 2-Dy, 4-Dy and 5-Dy, the most distorted geometry found in 2-Dy shows the modest energy barrier, whereas the highest energy barrier is found for the most ideal geometry present in compound 1-Dy. This fact points out that the larger the deviation of the coordination polyhedron with respect to ideal geometry the lower the value of $U_{\text {eff }}$, which is a consequence of the increase in the quantum tunneling process as already seen in previously reported works $[57,58]$. It must be remarked the case of compound 5-Dy, in which despite the fact that the spherical capped square antiprism geometry is more distorted than for compound 1-Dy (see Table S2), it presents a higher energy barrier for the reversal of the magnetization. This fact is related to the replacement of the oxalate for the nitrate anion. Taking into account that both co-ligands are located in the equatorial positions of their respective compounds, whose orientation of the magnetic moment has been confirmed using Chilton's electrostatic model (Figure S10) [59], the lower donor capacity of the nitrate compared to oxalate tends to better stabilize the ligand field and, therefore, a higher $U_{\text {eff }}$ value is achieved as previously seen for others Dy-SMM [60,61].

\subsection{Photoluminescence Properties}

The photoluminescence properties of the dysprosium(III)-based compounds as well as of the 4-Sm and 4-Eu were characterized in the solid state on polycrystalline samples with the aim of exploring the multifunctional character of the CPs. As previously mentioned, the photoluminescence properties of lanthanide(III)-based CPs depend to a large extent on the capacity of the ligands to promote the antenna effect, by which the lanthanide(III) ion provides bright or weak emission. To start with, emission spectra of the Dy(III) counterparts were analyzed using a monochromatic LASER light $\left(\lambda_{\mathrm{ex}}=325 \mathrm{~nm}\right)$ at room temperature. Despite the fact that all compounds share the occurrence of pmdc ligands, they present significantly different emission spectra due to a non-equivalent energy transfer from the 
ligand's excited states to excited intraionic levels of Dy(III) (Figure 9). In any case, two types of emission are distinguished in all cases: (i) a first wide and intense band peaking at $410 \mathrm{~nm}$ that is ascribed to the ligands emission, by comparison to the previously reported isostructural 3-Eu and 3-Tb counterparts [40], which is followed by (ii) the characteristic bands of Dy(III) based on its intraionic transitions. Among all compounds, the emission of 1-Dy is the most different, since the ligand-based band dominates the spectrum while only two weak Dy-based signals, peaking at 480 and $575 \mathrm{~nm}$ respectively for ${ }^{4} \mathrm{~F}_{9 / 2} \rightarrow$ ${ }^{6} \mathrm{H}_{15 / 2}$ and ${ }^{4} \mathrm{~F}_{9 / 2} \rightarrow{ }^{6} \mathrm{H}_{13 / 2}$ transitions, are observed. Conversely, the rest of compounds (2-Dy, 3-Dy, 4-Dy and 5-Dy) exhibit much intense Dy-based emissions compared to the initial more energetic ligand-based emission, indicating that the antenna effect takes place effectively on them. It is worth noting that four multiplets are observed in all these cases, with their maxima centred on 480 (for ${ }^{4} \mathrm{~F}_{9 / 2} \rightarrow{ }^{6} \mathrm{H}_{15 / 2}$ ), 575 (for ${ }^{4} \mathrm{~F}_{9 / 2} \rightarrow{ }^{6} \mathrm{H}_{13 / 2}$ ), 660 (for ${ }^{4} \mathrm{~F}_{9 / 2} \rightarrow{ }^{6} \mathrm{H}_{11 / 2}$ ) and 755 (for ${ }^{4} \mathrm{~F}_{9 / 2} \rightarrow{ }^{6} \mathrm{H}_{9 / 2}$ ) nm, among which the second one is the most intense in all cases and the third and fourth are quite weak. This pattern represents the most habitual scenario for Dy-based complexes and CPs, almost irrespective to the employed ligands [62,63]. Focusing on the main Dy-based emission $\left(\lambda_{\mathrm{em}} \approx 575 \mathrm{~nm}\right)$, the excitation spectra performed on the compounds offer a similar situation about the ligandto-Dy energy transfer except for 5-Dy (see ESI, Figure S11). In detail, all spectra share the presence of a wide band, ascribed to ligand excitation and peaking at $300 \mathrm{~nm}$, accompanied by a series of discrete maxima corresponding to direct intraionic excitations, which are clearly less intense than the first wide ligand-based band in compounds 2-Dy, 3-Dy, 4-Dy and of similar intensity for compound 1-Dy, whereas they clearly dominate the spectrum of 5-Dy. This fact confirms that an effective antennae effect may be expected for 2-Dy, 3-Dy, 4Dy but the much lower for 1-Dy, meanwhile no significant transfer could happen for 5-Dy (in which the wide band is hardly observed). With this conclusion in mind, the fact that Dybased emissions $\left(\lambda_{\mathrm{em}} \approx 480\right.$ and $575 \mathrm{~nm}$ ) are stronger for 5-Dy than 1-Dy must be attributed to the higher cross-section of the ${ }^{5} \mathrm{P}_{7 / 2} \leftarrow{ }^{6} \mathrm{H}_{9 / 2}\left(\lambda_{\text {ex }} \approx 326\right.$ and $328 \mathrm{~nm}$ respectively for 5-Dy than 1-Dy) transition due to a higher overlap with the monochromatic laser excitation $\left(\lambda_{\mathrm{ex}} \approx 325 \mathrm{~nm}\right)$. In any case, the fact that non-planar background is also observed for 5-Dy, attributed to the ligand-based wide band covering the 350-600 nm range, does not allow one to discard the occurrence of substantial ligand-mediated excitation occurring in this compound.
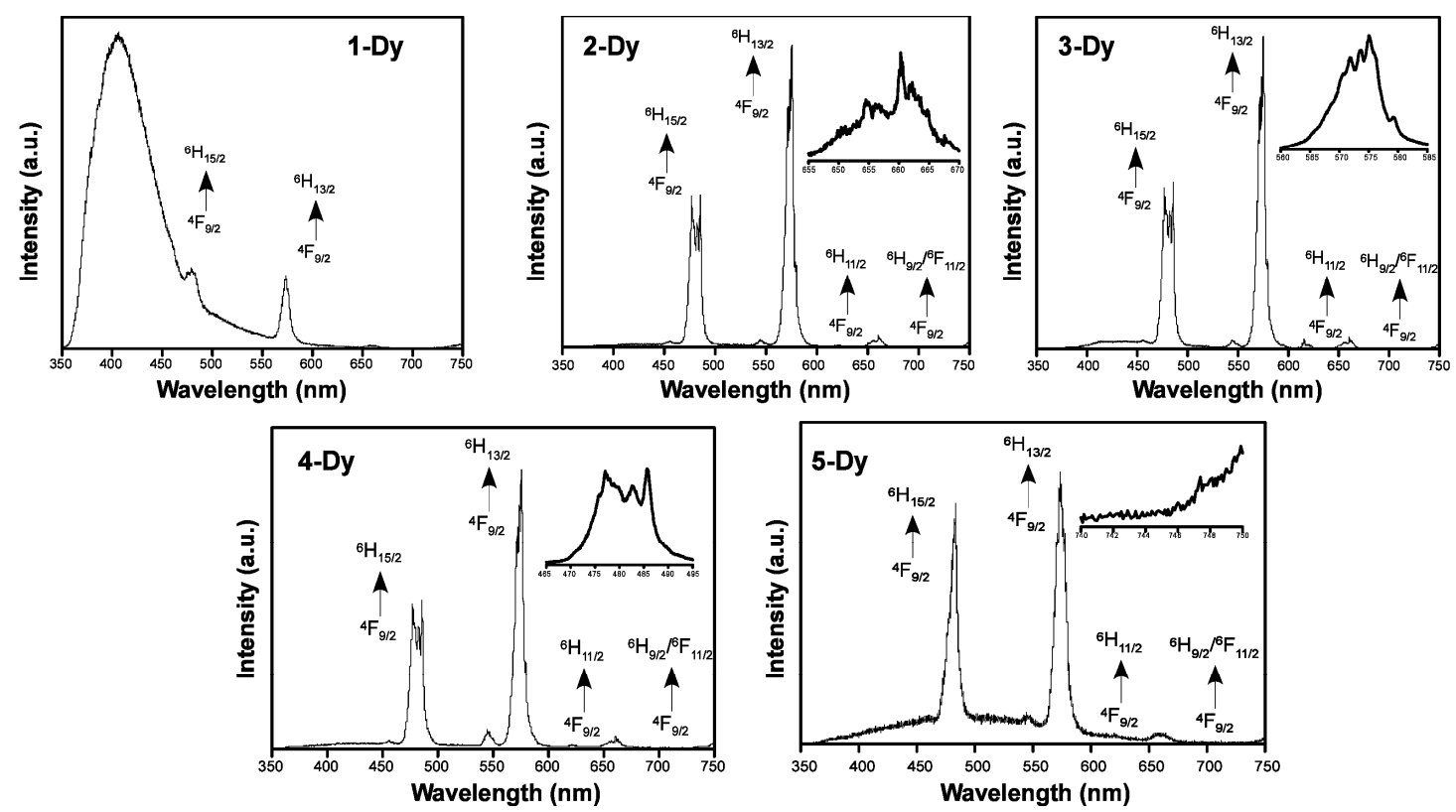

Figure 9. Emission spectra at room temperature for 1-Dy, 2-Dy, 3-Dy, 4-Dy and 5-Dy under excitation at $325 \mathrm{~nm}$. The insets show a detailed view of the multiplets for the Dy-centered ${ }^{6} \mathrm{H}_{J} \leftarrow{ }^{4} \mathrm{~F}_{9 / 2}$ intraionic transitions. 
The analysis of the decay curves measured (Figure S13) on the samples by means of the following exponential expression [Equation (2)] allowed us to estimate the emission lifetimes occurring from the excited ${ }^{4} \mathrm{~F}_{9 / 2}$ term of Dy(III) for these compounds (Table 2).

$$
\left[I_{t}=A_{0}+A_{1} \exp \left(-t / \tau_{1}\right)+A_{2} \exp \left(-t / \tau_{2}\right)\right]
$$

Table 2. Emission lifetimes and quantum yields measured for Dy-based compounds.

\begin{tabular}{cccc}
\hline \multirow{2}{*}{ Compound } & \multicolumn{2}{c}{ Lifetimes } & Quantum Yield (\%) \\
\cline { 2 - 4 } & $\tau_{\mathbf{1}}(\boldsymbol{\mu s})$ & $\boldsymbol{\tau}_{\mathbf{2}}(\boldsymbol{\mu} \mathbf{s})$ & \\
\hline 1-Dy & $7.73(9) / 100 \%$ & - & 2.0 \\
2-Dy & $5.73(6) / 97 \%$ & $34(11) / 3 \%$ & 2.9 \\
3-Dy & $5.44(7) / 94 \%$ & $19(3) / 6 \%$ & 2.4 \\
4-Dy & $5.66(11) / 88 \%$ & $16(2) / 12 \%$ & 2.2 \\
5-Dy [41] & $2.70(1) / 100 \%$ & - & 3.4 \\
\hline
\end{tabular}

As observed from these data, the emission lifetime does not show very dramatic changes with the replacement of ligands in the coordination sphere. Among them, it is worth highlighting that 5-Dy presents the highest emission Quantum Yield (QY) among all compounds, an enhancement that could have different origins. On the one hand, it seems quite reasonable that, consisting of purer Dy-based luminescence (following an intraionic excitation and subsequent emission involving the antennae effect to a lower extent, as pointed out before), the large QY could be explained by the less non-radiative loss happening in comparison to the pathway followed in the rest of compounds, where the excitation energy occurs mainly on the ligands and is transferred to Dy(III) centers, which probably involves higher non-radiative losses. The short lifetime observed for 5-Dy over the rest of compounds (with lifetimes of ca. $7 \mu \mathrm{s}$ ) point out in the same direction. On the other hand, the larger QY observed for 5-Dy may be also explained by the presence of nitrate anions acting as a coligands. Though no further analysis could be done on this issue, it may be speculated that the exchange of water molecules by a nitrate ligand in the coordination shell could better isolate the ${ }^{4} \mathrm{~F}_{9 / 2}$ emissive levels of Dy(III) ions from the vibrational quenching in the network, at least regarding the vibrations associated with the ligands. In this respect, coordination water molecules contain $\mathrm{O}-\mathrm{H}$ bonds, known to act as effective quenchers of $\mathrm{Ln}(\mathrm{III})$ centered luminescence [64-66], whereas $\mathrm{O}-\mathrm{N}$ vibrations are not easily coupled to energy gaps occurring in the lanthanide ion (for the emissive transitions). Therefore, the least intense emission observed in 1-Dy may be also related to the vibrational quenching being larger in this case owing to the higher amount of coordination water molecules ( 3 per Dy ion) compared to the rest of the structures.

When 4-Sm is exited with a $325 \mathrm{~nm}$ laser, a broad band at low wavelengths is observed which can be assigned to the ligand emission, followed by the characteristic emission bands for intraionic ${ }^{6} \mathrm{H}_{\mathrm{J}} \leftarrow{ }^{4} \mathrm{G}_{5 / 2}(\mathrm{~J}=5 / 2,7 / 2,9 / 2$ and 11/2) transitions of Sm(III) ion centered at 560, 595, 645 and $705 \mathrm{~nm}$ (Figure 10). Under the same conditions, 4-Eu does not show any emission below $580 \mathrm{~nm}$, which is indicative of a highly efficient energy transfer from the pmdc ligand to the excited intraionic Eu(III) ion excited levels. At higher wavelengths, five groups of signals are observed centered at 580,593, 618, 650 and $698 \mathrm{~nm}$ corresponding to the intraionic ${ }^{7} \mathrm{~F}_{J} \leftarrow{ }^{5} \mathrm{D}_{0}(J=0,1,2,3$ and 4$)$ transitions in the visible range spectrum (Figure 10). Recorded excitation spectra at the main emission wavelength for compounds 4-Sm $\left(\lambda_{\mathrm{em}} \approx 596 \mathrm{~nm}\right)$ and 4-Eu $\left(\lambda_{\mathrm{em}} \approx 618 \mathrm{~nm}\right)$ are in line with the Dy counterpart, with a wide band identified as the excitation of pmdc ligand, followed by several narrow peaks for intraionic excitations of the corresponding lanthanides (Figure S12). Note the high intensity band shown by 4 -Eu, a fact that points out the efficient antenna effect. 

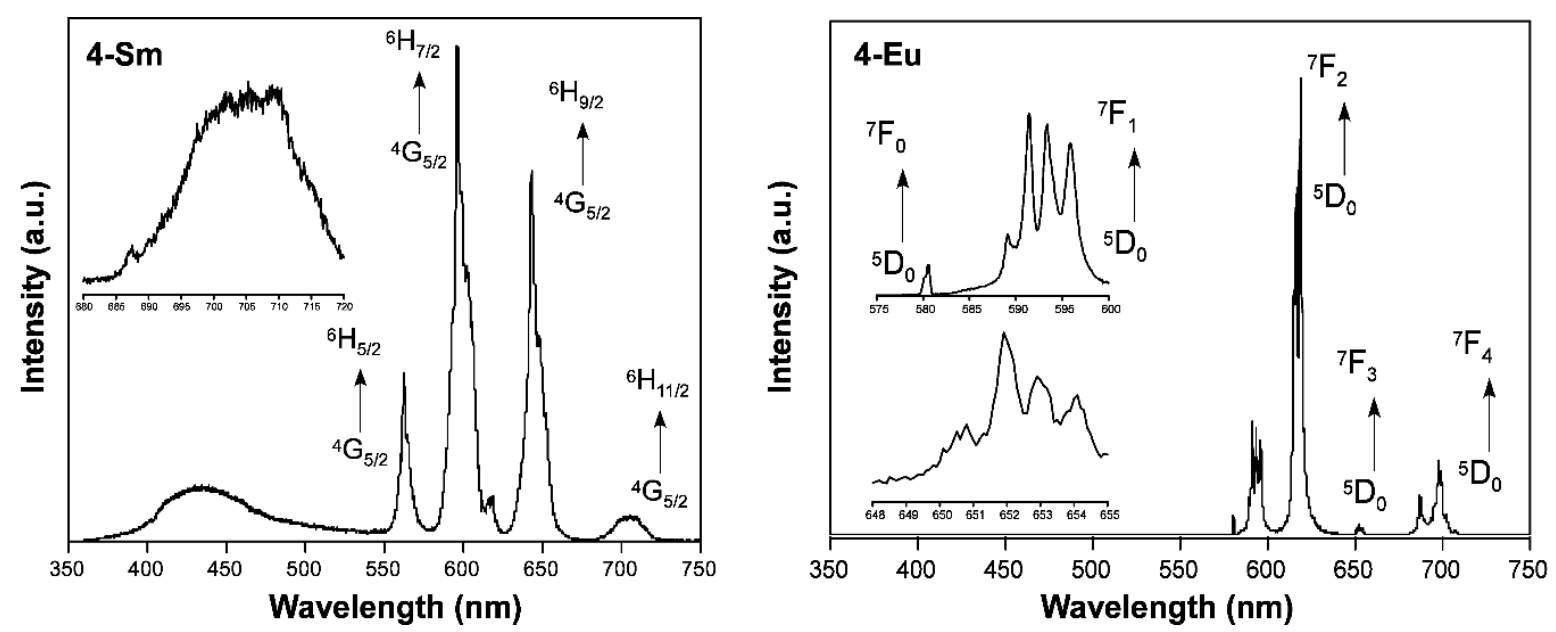

Figure 10. Room temperature emission spectra under excitation at $325 \mathrm{~nm}$ for compounds 4-Sm and 4-Eu.

To fully characterize photoluminescence properties of compounds 4-Sm and 4-Eu, decay curves acquired at room temperature were fitted to Equation (2) and the emission lifetimes were obtained (Figure S14). The curves were measured exciting the samples at 308 $\mathrm{nm}$ (to maximize the excitation ligand-centered band) and recording their main emission bands peaking at 595 and $618 \mathrm{~nm}$ for 4-Sm and 4-Eu, respectively. Best fit values, as well as QY are reported in Table 3.

Table 3. Emission lifetimes and quantum yields measured for 4-Sm and 4-Eu.

\begin{tabular}{ccccc}
\hline \multirow{2}{*}{ Compound } & \multicolumn{2}{c}{ Lifetimes } & \multicolumn{2}{c}{ Quantum Yield (\%) } \\
\cline { 2 - 5 } & $\boldsymbol{\tau}_{\mathbf{1}}(\boldsymbol{\mu} \mathbf{s})$ & $\boldsymbol{\tau}_{\mathbf{2}}(\boldsymbol{\mu} \mathbf{s})$ & Absolute $(\boldsymbol{\phi})$ & Lanthanide $(\boldsymbol{\phi L n})$ \\
\hline 4-Sm & $4.25(9) / 32 \%$ & $7.61(6) / 68 \%$ & 5.0 & 0.19 \\
4-Eu & $99(7) / 5 \%$ & $364(2) / 95 \%$ & 25.0 & 4.56 \\
\hline
\end{tabular}

In this case, despite the dual component observed from the fittings, the emission lifetimes are representatively characterized by the major second lifetime $\left(\tau_{2}\right)$. Comparing these results, it is not surprising that 4-Eu exhibits the longest emission lifetime among all the studied homologues since this metal ion usually presents good sensitization of carboxylate-based ligands $[67,68]$. In the present case, the better luminescence sensitization of pmdc ligand towards Eu(III) ion is compared to other lanthanides, a fact that can be also observed in the high QY, should come from a more efficient energy transfer from the ligand's triplet state to the excited emissive state of $\mathrm{Eu}(\mathrm{III})\left({ }^{5} \mathrm{D}_{0}\right)$. To that end, the ligand's excited state energy is determinant according to Latva's rule, according to which an energy gap between acceptor-receptor states must be of $2500-4000 \mathrm{~cm}^{-1}$ for efficient transfers [69]. According to previous studies [40], the experimentally determined triplet state of pmdc is of ca. 20,619 $\mathrm{cm}^{-1}$. Putting aside the larger natural emission lifetime of $\mathrm{Eu}(\mathrm{III})$ over the rest of the lanthanides [70], and taking into account that excited levels of lanthanides are at ca. $17,500 \mathrm{~cm}^{-1}$ for ${ }^{5} \mathrm{D}_{0}$ in $\mathrm{Eu}(\mathrm{III}), 17,730 \mathrm{~cm}^{-1}$ for ${ }^{4} \mathrm{G}_{5 / 2}$ in $\mathrm{Sm}(\mathrm{III})$ and $20,800 \mathrm{~cm}^{-1}$ for ${ }^{4} \mathrm{~F}_{9 / 2}$ in Dy(III), it may be explained by the fact that the emission in Dy(III)-based compounds is poorer than in Sm- and Eu-based ones, but the difference observed between 4-Sm and 4-Eu is not. In order to better explain this fact, we decided to compute the triplet state of pmdc ligand with DFT theory, which shifted the energy value to $24,000 \mathrm{~cm}^{-1}$ (see Figure S15) with respect to the ground single state. With this new value in mind, and in view of the large separation, it can be assumed that the energy transfer may be occurring between ligand's triplet state and above-lying excited states of lanthanides (III), among which ${ }^{5} \mathrm{D}_{2}$ in $\mathrm{Eu}$ (III) (at 21,200 $\mathrm{cm}^{-1}$ ) and ${ }^{4} \mathrm{I}_{9 / 2}\left(\right.$ at 20,500 $\mathrm{cm}^{-1}$ ) are known to act as accessorial levels to accept energy by a multipolar mechanism $[68,71]$. In any case, considering that radiative 
emission rate $\left(\tau_{R}\right)$ for these two ions are 7.7 and $3.3 \mathrm{~ms}$ according to bibliography [71,72], respectively for $\mathrm{Eu}(\mathrm{III})$ and $\mathrm{Sm}(\mathrm{III})$, the lanthanide emission quantum yield $\left(\phi_{\mathrm{Ln}}\right)$ calculated by means of Equation (3) (see Table 3) confirms the above mentioned best transfer for Eu(III) than for Sm(III).

$$
\phi_{L n}=\tau_{o b s} / \tau_{R}
$$

Note that values for $\tau_{o b s}$ have been estimated from the experimental mean lifetimes, i.e., on the basis of the proportional weight of the lifetime component. All in all, the obtained values for Sm(III)-based CP fall in the range of other complexes [73,74], whereas it must be underlined that $\mathrm{Eu}(\mathrm{III})$-based $\mathrm{CP}$ can be qualified in the mid-top range of complexes in terms of quantum efficiency [67].

\section{Materials and Methods}

Chemicals. All chemicals were of reagent grade and uses as commercially obtained with any further purification. The starting material pyrimidine-4,6-dicarboxylic acid $\left(\mathrm{H}_{2}\right.$ Pmdc) was prepared following the previously reported procedure [75].

Synthesis of $\left\{\left[\mathrm{Dy}(\mu \text {-pmdc })(\mu-o x)_{0.5}\left(\mathbf{H}_{\mathbf{2}} \mathbf{O}\right)_{3}\right] \cdot 2 \mathbf{H}_{\mathbf{2}} \mathrm{O}\right\}_{\mathbf{n}}(\mathbf{1 - D y}) . \mathrm{Dy}\left(\mathrm{NO}_{3}\right)_{3}(0.075 \mathrm{mmol}$, $0.0261 \mathrm{~g}$ ) was dissolved in $5 \mathrm{~mL}$ of water and the solution was added dropwise over another aqueous solution of $20 \mathrm{~mL}$ containing $\mathrm{H}_{2}$ Pmdc $(0.150 \mathrm{mmol}, 0.0306 \mathrm{~g})$ and kept under vigorous stirring at $60^{\circ} \mathrm{C}$ for $1 \mathrm{~h}$. The resulting solution was placed on a $45 \mathrm{~mL}$ Teflon-lined stainless autoclave under autogenous pressure at $120^{\circ} \mathrm{C}$ for 3 days and then slowly cooled down to room temperature $\left(2^{\circ} \mathrm{C} / \mathrm{h}\right)$.

Synthesis of $\left\{\left[\mathrm{Dy}\left(\mu_{3}-\mathrm{pmdc}\right)(\mu-\mathrm{ox})_{0.5}\left(\mathrm{H}_{2} \mathrm{O}\right)_{2}\right] \cdot \sim 2.33 \mathrm{H}_{2} \mathrm{O}\right\}_{\mathrm{n}}(2-\mathrm{Dy})$. High quality single crystals were obtained following the above-described procedure setting the temperature for hydrothermal treatment at $140{ }^{\circ} \mathrm{C}$.

Synthesis of $\left\{\left[\mathrm{Dy}_{2}\left(\mu_{3}-\mathrm{pmdc}\right)\left(\mu_{4}-\mathrm{pmdc}\right)(\mu-\mathrm{ox})\left(\mathrm{H}_{2} \mathrm{O}\right)_{3}\right] \cdot 5 \mathrm{H}_{2} \mathrm{O}\right\}_{\mathrm{n}}(3-\mathrm{Dy})$. Polycrystalline sample of 3 was prepared following the general procedure increasing the hydrothermal temperature to $160{ }^{\circ} \mathrm{C}$.

Synthesis of $\left\{\left[\operatorname{Ln}\left(\mu_{3}-\mathrm{pmdc}\right)(\mu-\mathrm{ox})_{0.5}\left(\mathrm{H}_{2} \mathrm{O}\right)_{2}\right] \cdot \mathrm{H}_{2} \mathrm{O}\right\}_{n}(\operatorname{Ln}=\mathrm{Nd}(4-\mathrm{Nd}), \mathrm{Sm}(4-\mathrm{Sm})$, $\mathrm{Eu}$ (4-Eu) and Dy (4-Dy)). Single crystals of 4-Nd, 4-Sm and 4-Eu were grown increasing the hydrothermal temperature to $180^{\circ} \mathrm{C}$. No single crystals could be achieved for the 4-Dy counterpart, though it was purely obtained as polycrystalline powder.

Synthesis of $\left\{\left[\mathrm{Dy}\left(\mu_{4} \text {-pmdc) }\left(\mathrm{NO}_{3}\right)\left(\mathrm{H}_{2} \mathrm{O}\right)\right] \cdot \mathrm{H}_{2} \mathrm{O}\right\}_{\mathrm{n}}(5-\mathrm{Dy})\right.$. A polycrystalline sample of 5-Dy was obtained by following the previously reported solvent-free procedure as detailed before [41]. In short, it consisted of hand-grinding a mixture of $\mathrm{Dy}\left(\mathrm{NO}_{3}\right)_{3}(0.200 \mathrm{mmol}$, $0.0697 \mathrm{~g})$ and $\mathrm{H}_{2}$ pmdc $(0.2 \mathrm{mmol}, 0.0408 \mathrm{~g})$ to obtain a homogeneous mixture, which was sealed in a glass vacule and slowly heated up to $190^{\circ} \mathrm{C}$ for $48 \mathrm{~h}$. Finally, the sample was slowly cooled down to room temperature $\left(4^{\circ} \mathrm{C} / \mathrm{h}\right)$ and washed several times with water and methanol to ensure the removal of starting reagents.

X-ray Diffraction Data Collection and Structure Determination. Single-crystal diffraction data were collected at 100(2) K on an Oxford Diffraction Xcalibur diffractometer with graphite-monochromomated Mo $\mathrm{K} \alpha$ radiation $(\lambda=0.71073 \AA)$. Data reduction for compounds 1-Ln-3-Ln and 5-Ln was detailed elsewhere [40,41]. Data integration of compounds 4-Nd, 4-Sm and 4-Eu was carried out with the CrysAlis Pro program [76], and using the twin laws specified in the cif files given the non-merohedric twins found in all cases. The component for the minor domain was 22, 26 and $42 \%$ respectively for 4-Nd, 4-Sm and 4-Eu. These structures were solved by direct methods using the SHELXT program [77] and refined by full-matrix least-squares of $\mathrm{F}^{2}$ including all reflections with SHELXL-2018/3 program [78]. All calculations for these structures were performed using the WINGX crystallographic software package [79]. Table S1 gathers the most remarkable crystallographic data for the three novel crystal structures. CCDC 825170 and 825176 contain the supplementary crystallographic data for previously reported compounds 1-Dy and 2-Dy whereas CCDC 2048324-2048326 contains the structures of compounds 4-Nd, 4-Sm and 4-Eu. These data are provided free of charge by the Cambridge Crystallographic Data Centre via www.ccdc.cam.ac.uk/data_request/cif. 
The X-ray powder diffractions (XRPD) patterns were collected on a Philips X'PERT powder diffractometer with $\mathrm{Cu} \mathrm{K} \alpha$ radiation $(\lambda=1.5418 \AA)$ over the $5<2 \theta<50^{\circ}$ range with a step size of $0.02^{\circ}$ and an acquisition time of $2.5 \mathrm{~s}$ per step at $25^{\circ} \mathrm{C}$. Indexation of the diffraction profiles were carried out using the FULLPROF program [80], on the basis of the space group and cell parameters found for isostructural compounds by single crystal X-ray diffraction.

Physical measurements. Infrared (IR) spectra were recorded for the novel compounds 4-Nd, 4-Sm, 4-Eu and 4-Dy (Figures S16 and S17) using KBr pellets on a Thermo-Nicolet IR 200 spectrometer in the $4000-400 \mathrm{~cm}^{-1}$ range. Recorded IR spectra can be found in the ESI. The variable temperature magnetic susceptibility measurements were performed on polycrystalline samples with a Quantum Design SQUID susceptometer covering the 2-300 $\mathrm{K}$ temperature range at a magnetic field of $1000 \mathrm{G}$. The susceptibility data were corrected for the diamagnetism estimated from Pascal's tables [81], the temperature-independent paramagnetism and the magnetization of the sample holder. Alternating current $(a c)$ magnetic measurements were recorded on a PPMS (physical property measurement system) Quantum Design model 6000 magnetometer under a 3.5 G ac field and frequencies ranging from 60 to $10,000 \mathrm{~Hz}$.

Photoluminescence measurements. Photoluminescence spectra were recorded on an Edinburgh Instruments FLS920 spectrometer done using a close cycle helium cryostat. All measurements were performed under high vacuum (of ca. $10^{-9} \mathrm{mbar}$ ) to avoid the presence of oxygen or water in the sample holder. For steady-state measurements, an IK3552R-G HeCd continuous laser $(325 \mathrm{~nm})$ was used as excitation source, whereas a Müller-ElektronikOptik SVX1450 Xe lamp was employed to collect the excitation spectra. On the other hand, the decay curves were measured using a $\mu \mathrm{F} 900$ microsecond pulsed lamp for the lanthanide (III)-based emissions or a pulsed laser diode LDH-P-C-375 $(\lambda=375 \mathrm{~nm})$ for the ligand-based emissions. The analysis of the fluorescence in the ultraviolet-visible (UV-Vis) region was done with photomultiplier tube (PMT) coupled to the spectrometer (1-Dy, 2-Dy, 3-Dy, 4-Sm, 4-Eu, 4-Dy and 5-Dy). The overall quantum yield (\%) was measured in solid state for all samples (except for 4-Nd) by means of a Horiba Quanta- $\varphi$ integrating sphere using an Oriel Instruments MS257 lamp as excitation source and an iHR550 spectrometer from Horiba to analyse the emission.

Computational details. The magnetic coupling constant (Jcalc) was computed with the broken symmetry strategy described and validated elsewhere [82], using the Gaussian 16 package [83]. Spin density distribution was checked to ensure the correctness of the method, which consisted of the hybrid B3LYP functional and Gaussian-implemented 6$311 \mathrm{G}(\mathrm{d})$ basis set for all atoms but for the metal atom, which was computed with CRENBL pseudopotential. Spin-density surfaces were built with GaussView 5 [84]. On another level, the anisotropy axis of the Dy(III) ions was calculated with Magellan software [59]. Regarding the calculation of the triplet state of pmdc ligand, a geometry optimization plus frequencies calculations were done using the unrestricted wave-function (UKS) within the Kohn-Sham DFT by means of Gaussian 16 package. B3LYP functional with the 6$311 \mathrm{G}++(\mathrm{d}, \mathrm{p})$ basis set for all atoms was employed. The energy was estimated as a vertical excitation following the methodology reported for other works [85].

\section{Conclusions}

In summary, five different families of Ln-OF have been synthetized by the combination of lanthanide(III) ions, pmdc organic ligand and an additional co-ligand, which is oxalate for 1-Dy, 2-Dy, 3-Dy and 4-Ln and nitrate anion for 5-Dy. Magnetic measurements carried out under static $d c$ field over Dy-based compounds show almost negligible interactions among metal centers, a fact that is also supported by the computed DFT calculations, meaning that metal centers are practically isolated. Moreover, ac magnetic susceptibility measurements revealed the field-induced SMM behavior of compounds 1-Dy, 2-Dy, 4-Dy and 5-Dy reveals that the energy barrier for the reversal of the magnetization is highly dependent on the coordination environment, in the way that higher energy barriers are 
achieved for the most ideal polyhedra. Nonetheless, the replacement of oxalate ligand by nitrate anion in the equatorial plane leads to a higher stabilization of the ligand field and thus, a higher energy barrier in spite of the fact that 5-Dy presents a more distorted polyhedron. On the other hand, the photoluminescence emission spectra recorded for the Dy-based compounds, as well as for 4-Sm and 4-Eu compounds, show the characteristic emission peaks for each lanthanide(III) ions in the visible region as a consequence of the $\mathrm{f}-\mathrm{f}$ intraionic transitions, in addition to the weaker ligand based emission. The relative intensity of the ligand-based emission and f-f intraionic transitions vary for Dy-based compounds, which is explained by different effects. On the one hand, a variable change in the effectiveness of the ligand-to-lanthanide energy transfer due to the changes occurring in the coordination shell of the structures, which is mainly observed when comparing the stronger emissions for 3D systems of 2-Dy, 3-Dy and 4-Dy to the 2D system of 1-Dy. On the other hand, the bright Dy-based emission observed for 5-Dy seems to proceed through a direct Dy-centered intraionic excitation, which bypasses the ligand excitation and associated antennae effect and helps decreasing the non-radiative pathways within the $\mathrm{CP}$, in such a way the 5-Dy yields the most effective emission for all analyzed Dy-based compounds. On another level, the analysis on the rest of the counterparts (4-Sm and 4-Eu) shows that the antennae effect is presumably maximized for 4-Eu in view of the similar energy of triplet state of pmdc ligand and the excited states of Eu(III) ion, in such a way that 4-Eu affords a QY of $25 \%$ at room temperature.

Supplementary Materials: The following are available online at https://www.mdpi.com/2312-7 481/7/1/8/s1. The ESI file includes Fourier Transform Infrared (FTIR) spectra, Powder X-Ray Diffraction (PXRD) analysis, crystallographic data, structural details, ac magnetic susceptibility measurements, photoluminescence measurements and computational calculation of the triplet state. Figure S1: Pattern-matching analyses of previously reported Dy-based compounds Figure S2: Patternmatching analyses for 4-Nd, 4-Sm, 4-Eu and 4-Dy, Figure S3: $\chi \mathrm{M}^{\prime}(\mathrm{T})$ and $\chi \mathrm{M}^{\prime \prime}(\mathrm{T})$ signals plots for compound 3-Dy under $\mathrm{H}_{\mathrm{dc}}=1000$ Oe, Figures S4 and S5: Temperature dependence of in-phase components of the ac susceptibility in a dc applied field of 1000 Oe for 1-Dy, 2-Dy, 4-Dy and 5-Dy Figures S6 and S7: Cole-Cole plots in dc applied field of 1000 Oe for 1-Dy, 2-Dy, 4-Dy and 5-Dy, Figure S8 and S9: Variable-temperature frequency dependence of the $\chi_{\mathrm{M}}{ }^{\prime \prime}$ ' signal under 1000 Oe applied field of 1-Dy, 2-Dy, 4-Dy and 5-Dy, Figure S10: Theoretical orientation of the magnetic moments for Dy(III) ions in compounds 1-Dy and 5-Dy, Figure S11: Excitation spectra monitored at $573 \mathrm{~nm}$ for compounds 1-Dy, 2-Dy, 3-Dy, 4-Dy and 5-Dy, Figure S12: Excitation spectra monitored at $596 \mathrm{~nm}$ for 4-Sm and at $618 \mathrm{~nm}$ for 4-Eu, Figure S13: Emission decay curves for compounds 1-Dy, 2-Dy, 3-Dy, 4-Dy and 5-Dy under $325 \mathrm{~nm}$ excitation laser showing the best fitting, Figure S14: Emission decay curves for compounds 4-Sm and 4-Eu under $308 \mathrm{~nm}$ excitation laser showing the best fitting, Figure S15: Illustration of the triplet and ground single state of pmdc ligand with the energy gap between them, Figure S16: IR spectra of 4-Nd, 4-Sm, 4-Eu and 4-Dy, Figure S17: FTIR spectra of all Dy-based compounds, Table S1: Crystallographic data for compounds 4-Nd, 4-Sm and 4-Eu, Table S2: CShMs for the coordination environment of compounds 1-Dy, 2-Dy, 3-Gd, 4-Nd, 4-Sm, 4-Eu and 5-Gd, Table S3: Selected bond lengths ( $\AA$ ) for compounds 1-Dy, 2-Dy, 4-Nd, 4-Sm and 4-Eu, Table S4: Relaxation Fitting Parameters from Least-Squares Fitting of $\chi(\phi)$ data for compound 2-Dy.

Author Contributions: Conceptualization, J.C. and A.R.-D.; synthesis of the samples, O.P.-C.; structural analysis, A.R.-D. and J.C.; validation, J.C., O.C. and J.A.G.; formal analysis, resources, O.C. and J.A.G.; data curation of PL, J.A.G.; data curation of magnetism, O.P.-C.; writing —original draft preparation, O.P.-C and J.C.; writing-review and editing, O.C. and A.L.; supervision, O.C. and A.L.; project administration, J.C.; funding acquisition, O.C. All authors have read and agreed to the published version of the manuscript.

Funding: This work was supported by the Spanish Ministry of Science, Innovation and Universities (MCIU / AEI/FEDER, UE) (PGC2018-102052-A-C22, PGC2018-102052-B-C21, PID2019-108028GBC21), Junta de Andalucía (FQM-394), Gobierno Vasco/Eusko Jaurlaritza (IT1005-16, IT1291-19) and University of the Basque Country (UPV/EHU) (GIU 17/13, GIU17/50).

Data Availability Statement: The data presented in this study are available in this article or Supplementary Material. 
Conflicts of Interest: The authors declare no conflict of interest.

\section{References}

1. Meek, S.T.; Greathouse, J.A.; Allendorf, M.D. Metal-Organic Frameworks: A Rapidly Growing Class of Versatile Nanoporous Materials. Adv. Mater. 2011, 23, 249-267. [CrossRef] [PubMed]

2. Cheetham, A.K.; Rao, C.N.R. There's Room in the Middle. Science 2007, 318, 58-59. [CrossRef] [PubMed]

3. Yamada, T.; Otsubo, K.; Makiura, R.; Kitagawa, H. Designer coordination polymers: Dimensional crossover architectures and proton conduction. Chem. Soc. Rev. 2013, 42, 6655-6669. [CrossRef] [PubMed]

4. Hang, T.; Zhang, W.; Ye, H.-Y.; Xiong, R.-G. Metal-organic complex ferroelectrics. Chem. Soc. Rev. 2011, 40, 3577-3598. [CrossRef] [PubMed]

5. $\quad$ Benoit, V.; Chanut, N.; Pillai, R.S.; Benzaqui, M.; Beurroies, I.; Devautour-Vinot, S.; Serre, C.; Steunou, N.; Maurin, G.; Llewellyn, P.L. A promising metal-organic framework (MOF), MIL-96(Al), for $\mathrm{CO}_{2}$ separation under humid conditions. J. Mater. Chem. A 2018, 6, 2081-2090. [CrossRef]

6. Hu, Z.; Wang, Y.; Shah, B.B.; Zhao, D. $\mathrm{CO}_{2}$ Capture in Metal-Organic Framework Adsorbents: An Engineering Perspective. Adv. Sustain. Syst. 2019, 3, 1800080. [CrossRef]

7. Salehi, S.; Anbia, M. High $\mathrm{CO}_{2}$ Adsorption Capacity and $\mathrm{CO}_{2} / \mathrm{CH}_{4}$ Selectivity by Nanocomposites of MOF-199. Energy Fuels 2017, 31, 5376-5384. [CrossRef]

8. Cepeda, J.; Pérez-Mendoza, M.; Calahorro, A.J.; Casati, N.; Seco, J.M.; Aragones-Anglada, M.; Moghadam, P.Z.; Fairen-Jimenez, D.; Rodríguez-Diéguez, A. Modulation of pore shape and adsorption selectivity by ligand functionalization in a series of "rob"-like flexible metal-organic frameworks. J. Mater. Chem. A 2018, 6, 17409-17416. [CrossRef]

9. Alrubaye, R.T.A.; Kareem, H.M. Carbon Dioxide Adsorption on MOF-199 Metal-Organic Framework at High Pressure. IOP Conf. Ser. Mater. Sci. Eng. 2019, 557, 12060. [CrossRef]

10. Zhang, Q.; Cui, Y.; Qian, G. Goal-directed design of metal-organic frameworks for liquid-phase adsorption and separation. Coord. Chem. Rev. 2019, 378, 310-332. [CrossRef]

11. Horcajada, P.; Gref, R.; Baati, T.; Allan, P.K.; Maurin, G.; Couvreur, P.; Férey, G.; Morris, R.E.; Serre, C. Metal-Organic Frameworks in Biomedicine. Chem. Rev. 2012, 112, 1232-1268. [CrossRef] [PubMed]

12. Cao, J.; Li, X.; Tian, H. Metal-Organic Framework (MOF)-Based Drug Delivery. Curr. Med. Chem. 2020, 27, 5949-5969. [CrossRef] [PubMed]

13. Yang, Q.; Xu, Q.; Jiang, H.-L. Metal-organic frameworks meet metal nanoparticles: Synergistic effect for enhanced catalysis. Chem. Soc. Rev. 2017, 46, 4774-4808. [CrossRef] [PubMed]

14. Mínguez, E.G.; Coronado, E. Magnetic functionalities in MOFs: From the framework to the pore. Chem. Soc. Rev. 2018, 47, 533-557. [CrossRef]

15. Errulat, D.; Marin, R.; Gálico, D.A.; Harriman, K.L.M.; Pialat, A.; Gabidullin, B.; Iikawa, F.; Couto, O.D.D.; Moilanen, J.O.; Hemmer, E.; et al. A Luminescent Thermometer Exhibiting Slow Relaxation of the Magnetization: Toward Self-Monitored Building Blocks for Next-Generation Optomagnetic Devices. ACS Cent. Sci. 2019, 5, 1187-1198. [CrossRef]

16. Xin, Y.; Wang, J.; Zychowicz, M.; Zakrzewski, J.J.; Nakabayashi, K.; Sieklucka, B.; Chorazy, S.; Ohkoshi, S. Dehydration-Hydration Switching of Single-Molecule Magnet Behavior and Visible Photoluminescence in a Cyanido-Bridged DyIIICoIII Framework. J. Am. Chem. Soc. 2019, 141, 18211-18220. [CrossRef]

17. Cui, Y.; Yue, Y.; Qian, G.; Chen, B. Luminescent Functional Metal-Organic Frameworks. Chem. Rev. 2012, 112, 1126-1162. [CrossRef]

18. Long, J.; Guari, Y.; Ferreira, R.A.S.; Carlos, L.D.; Larionova, J. Recent advances in luminescent lanthanide based Single-Molecule Magnets. Coord. Chem. Rev. 2018, 363, 57-70. [CrossRef]

19. Kreno, L.E.; Leong, K.; Farha, O.K.; Allendorf, M.; Van Duyne, R.P.; Hupp, J.T. Metal-Organic Framework Materials as Chemical Sensors. Chem. Rev. 2012, 112, 1105-1125. [CrossRef]

20. Falcaro, P.; Ricco, R.; Doherty, C.M.; Liang, K.; Hill, A.J.; Styles, M.J. MOF positioning technology and device fabrication. Chem. Soc. Rev. 2014, 43, 5513-5560. [CrossRef]

21. San Sebastian, E.; Cepeda, J.; Huizi-Rayo, U.; Terenzi, A.; Finkelstein-Shapiro, D.; Padro, D.; Santos, J.I.; Matxain, J.M.; Ugalde, J.M.; Mujica, V. Enantiospecific Response in Cross-Polarization Solid-State Nuclear Magnetic Resonance of Optically Active Metal Organic Frameworks. J. Am. Chem. Soc. 2020, 142, 17989-17996. [CrossRef] [PubMed]

22. Huizi-Rayo, U.; Gutierrez, J.; Seco, J.M.; Mujica, V.; Diez-Perez, I.; Ugalde, J.M.; Tercjak, A.; Cepeda, J.; San Sebastian, E. An Ideal Spin Filter: Long-Range, High-Spin Selectivity in Chiral Helicoidal 3-Dimensional Metal Organic Frameworks. Nano Lett. 2020, 20, 8476-8482. [CrossRef] [PubMed]

23. Frost, J.M.; Harriman, K.L.M.; Murugesu, M. The rise of 3-d single-ion magnets in molecular magnetism: Towards materials from molecules? Chem. Sci. 2016, 7, 2470-2491. [CrossRef] [PubMed]

24. Craig, G.A.; Murrie, M. 3D Single-Ion Magnets. Chem. Soc. Rev. 2015, 44, 2135-2147. [CrossRef] [PubMed]

25. Jia, J.-H.; Li, Q.-W.; Chen, Y.-C.; Liu, J.-L.; Tong, M.-L. Luminescent single-molecule magnets based on lanthanides: Design strategies, recent advances and magneto-luminescent studies. Coord. Chem. Rev. 2019, 378, 365-381. [CrossRef] 
26. Bi, Y.; Chen, C.; Zhao, Y.-F.; Zhang, Y.-Q.; Jiang, S.-D.; Wang, B.-W.; Han, J.-B.; Sun, J.-L.; Bian, Z.-Q.; Wang, Z.-M.; et al. Thermostability and photoluminescence of Dy(iii) single-molecule magnets under a magnetic field. Chem. Sci. 2016, 7, 5020-5031. [CrossRef]

27. Almeida Paz, F.A.; Klinowski, J.; Vilela, S.M.F.; Tomé, J.P.C.; Cavaleiro, J.A.S.; Rocha, J. Ligand design for functional metal-organic frameworks. Chem. Soc. Rev. 2012, 41, 1088-1110. [CrossRef]

28. Binnemans, K. Lanthanide-Based Luminescent Hybrid Materials. Chem. Rev. 2009, 109, 4283-4374. [CrossRef]

29. Woodruff, D.N.; Winpenny, R.E.P.; Layfield, R.A. Lanthanide Single-Molecule Magnets. Chem. Rev. 2013, 113, 5110-5148. [CrossRef]

30. Kuznetsova, A.; Matveevskaya, V.; Pavlov, D.; Yakunenkov, A.; Potapov, A. Coordination polymers based on highly emissive ligands: Synthesis and functional properties. Materials 2020, 13, 2699. [CrossRef]

31. Shmelev, M.A.; Kiskin, M.A.; Voronina, J.K.; Babeshkin, K.A.; Efimov, N.N.; Varaksina, E.A.; Korshunov, V.M.; Taydakov, I.V.; Gogoleva, N.V.; Sidorov, A.A.; et al. Molecular and polymer $\ln 2 \mathrm{~m} 2$ (Ln = eu, gd, tb, dy; $\mathrm{m}=\mathrm{zn}$, cd) complexes with pentafluorobenzoate anions: The role of temperature and stacking effects in the structure; magnetic and luminescent properties. Materials 2020, 13, 5689. [CrossRef] [PubMed]

32. Baldoví, J.J.; Coronado, E.; Gaita-Ariño, A.; Gamer, C.; Giménez-Marqués, M.; Espallargas, G.M. A SIM-MOF: Three-Dimensional Organisation of Single-Ion Magnets with Anion-Exchange Capabilities. Chem. A Eur. J. 2014, 20, 10695-10702. [CrossRef] [PubMed]

33. Sessoli, R.; Powell, A.K. Strategies towards single molecule magnets based on lanthanide ions. Coord. Chem. Rev. 2009, 253, 2328-2341. [CrossRef]

34. Guo, F.-S.; Day, B.M.; Chen, Y.-C.; Tong, M.-L.; Mansikkamäki, A.; Layfield, R.A. Magnetic hysteresis up to 80 kelvin in a dysprosium metallocene single-molecule magnet. Science 2018, 362, 1400-1403. [CrossRef]

35. Bünzli, J.-C.G.; Piguet, C. Taking advantage of luminescent lanthanide ions. Chem. Soc. Rev. 2005, 34, 1048-1077. [CrossRef]

36. Heine, J.; Müller-Buschbaum, K. Engineering metal-based luminescence in coordination polymers and metal-organic frameworks. Chem. Soc. Rev. 2013, 42, 9232-9242. [CrossRef]

37. Barry, D.E.; Caffrey, D.F.; Gunnlaugsson, T. Lanthanide-directed synthesis of luminescent self-assembly supramolecular structures and mechanically bonded systems from acyclic coordinating organic ligands. Chem. Soc. Rev. 2016, 45, 3244-3274. [CrossRef]

38. Huizi-Rayo, U.; Zabala-Lekuona, A.; Terenzi, A.; Cruz, C.M.; Cuerva, J.M.; Rodríguez-Diéguez, A.; García, J.A.; Seco, J.M.; San Sebastian, E.; Cepeda, J. Influence of thermally induced structural transformations on the magnetic and luminescence properties of tartrate-based chiral lanthanide organic-frameworks. J. Mater. Chem. C 2020, 8, 8243-8256. [CrossRef]

39. Cepeda, J.; Beobide, G.; Castillo, O.; Luque, A.; Pérez-Yáñez, S. Structural diversity of coordination compounds derived from double-chelating and planar diazinedicarboxylate ligands. Coord. Chem. Rev. 2017, 352, 83-107. [CrossRef]

40. Cepeda, J.; Balda, R.; Beobide, G.; Castillo, O.; Fernández, J.; Luque, A.; Pérez-Yáñez, S.; Román, P.; Vallejo-Sánchez, D. Lanthanide(III)/Pyrimidine-4,6-dicarboxylate/Oxalate Extended Frameworks: A Detailed Study Based on the Lanthanide Contraction and Temperature Effects. Inorg. Chem. 2011, 50, 8437-8451. [CrossRef]

41. Cepeda, J.; Pérez-Yáñez, S.; Beobide, G.; Castillo, O.; García, J.Á.; Lanchas, M.; Luque, A. Enhancing luminescence properties of lanthanide(iii)/pyrimidine-4,6-dicarboxylato system by solvent-free approach. Dalt. Trans. 2015, 44, 6972-6986. [CrossRef] [PubMed]

42. Knope, K.E.; Kimura, H.; Yasaka, Y.; Nakahara, M.; Andrews, M.B.; Cahill, C.L. Investigation of in Situ Oxalate Formation from 2,3-Pyrazinedicarboxylate under Hydrothermal Conditions Using Nuclear Magnetic Resonance Spectroscopy. Inorg. Chem. 2012, 51, 3883-3890. [CrossRef] [PubMed]

43. Pearson, R.G. Hard and Soft Acids and Bases. J. Am. Chem. Soc. 1963, 85, 3533-3539. [CrossRef]

44. Mahata, P.; Prabu, M.; Natarajan, S. Role of Temperature and Time in the Formation of Infinite $-\mathrm{M}-\mathrm{O}-\mathrm{M}-\mathrm{Linkages}$ and Isolated Clusters in MOFs: A Few Illustrative Examples. Inorg. Chem. 2008, 47, 8451-8463. [CrossRef] [PubMed]

45. Forster, P.M.; Burbank, A.R.; Livage, C.; Férey, G.; Cheetham, A.K. The role of temperature in the synthesis of hybrid inorganicorganic materials: The example of cobalt succinates. Chem. Commun. 2004, 368-369. [CrossRef] [PubMed]

46. Jia, L.; Hui, Y.C.; Li, Z.; Sun, H.L.; Wang, Z. Luminescent lanthanide-2-phenylpyrimidine-carboxylate frameworks: Structure and luminescence tuning. CrystEngComm. 2014, 16, 6483-6490. [CrossRef]

47. Cepeda, J.; Balda, R.; Beobide, G.; Castillo, O.; Fernández, J.; Luque, A.; Pérez-Yáñez, S.; Román, P. Synthetic control to achieve lanthanide(III)/pyrimidine-4,6-dicarboxylate compounds by preventing oxalate formation: Structural, magnetic, and luminescent properties. Inorg. Chem. 2012, 51, 7875-7888. [CrossRef]

48. Sun, H.L.; Yin, D.D.; Chen, Q.; Wang, Z. Europium pyrimidine-4,6-dicarboxylate framework with a single-crystal-to- single-crystal transition and a reversible dehydration/rehydration process. Inorg. Chem. 2013, 52, 3582-3584. [CrossRef]

49. Alvarez, S.; Avnir, D.; Llunell, M.; Pinsky, M. Continuous symmetry maps and shape classification. The case of six-coordinated metal compounds. New J. Chem. 2002, 26, 996-1009. [CrossRef]

50. Dey, A.; Kalita, P.; Chandrasekhar, V. Lanthanide(III)-Based Single-Ion Magnets. ACS Omega 2018, 3, 9462-9475. [CrossRef]

51. Ion, A.E.; Nica, S.; Madalan, A.M.; Shova, S.; Vallejo, J.; Julve, M.; Lloret, F.; Andruh, M. Two-Dimensional Coordination Polymers Constructed Using, Simultaneously, Linear and Angular Spacers and Cobalt(II) Nodes. New Examples of Networks of Single-Ion Magnets. Inorg. Chem. 2015, 54, 16-18. [CrossRef] [PubMed] 
52. García-Valdivia, A.A.; Seco, J.M.; Cepeda, J.; Rodríguez-Diéguez, A. Designing Single-Ion Magnets and Phosphorescent Materials with 1-Methylimidazole-5-carboxylate and Transition-Metal Ions. Inorg. Chem. 2017, 56, 13897-13912. [CrossRef]

53. Pajuelo-Corral, O.; Zabala-Lekuona, A.; San Sebastian, E.; Rodríguez-Diéguez, A.; García, J.A.; Lezama, L.; Colacio, E.; Seco, J.M.; Cepeda, J. Modulating Magnetic and Photoluminescence Properties in 2-Aminonicotinate-Based Bifunctional Coordination Polymers by Merging 3d Metal Ions. Chem. A Eur. J. 2020, 26, 13484-13498. [CrossRef] [PubMed]

54. Chilton, N.M. CCFIT Program; The Chilton Group: Manchester, UK, 2014; Available online: http:/ / www.nfchilton.com/software. html (accessed on 15 November 2020).

55. Petrosyants, S.P.; Babeshkin, K.A.; Gavrikov, A.V.; Ilyukhin, A.B.; Belova, E.V.; Efimov, N.N. Towards comparative investigation of Er- and Yb-based SMMs: The effect of the coordination environment configuration on the magnetic relaxation in the series of heteroleptic thiocyanate complexes. Dalt. Trans. 2019, 48, 12644-12655. [CrossRef] [PubMed]

56. Langley, S.K.; Vignesh, K.R.; Holton, K.; Benjamin, S.; Hix, G.B.; Phonsri, W.; Moubaraki, B.; Murray, K.S.; Rajaraman, G. Mononuclear dysprosium(III) complexes with triphenylphosphine oxide ligands: Controlling the coordination environment and magnetic anisotropy. Inorganics 2018, 6, 61. [CrossRef]

57. She, S.; Gu, X.; Yang, Y. Field-induced single molecule magnet behavior of a three-dimensional Dy(III)-based complex. Inorg. Chem. Commun. 2019, 110, 107584. [CrossRef]

58. Guo, M.; Xu, Y.; Wu, J.; Zhao, L.; Tang, J. Geometry and magnetic interaction modulations in dinuclear Dy2 single-molecule magnets. Dalt. Trans. 2017, 46, 8252-8258. [CrossRef]

59. Chilton, N.F.; Collison, D.; McInnes, E.J.L.; Winpenny, R.E.P.; Soncini, A. An electrostatic model for the determination of magnetic anisotropy in dysprosium complexes. Nat. Commun. 2013, 4, 2551. [CrossRef]

60. Yao, X.; Yan, P.; An, G.; Li, Y.; Li, W.; Li, G. Investigation of magneto-structural correlation based on a series of seven-coordinated $\beta$-diketone Dy(iii) single-ion magnets with C2v and C3v local symmetry. Dalt. Trans. 2018, 47, 3976-3984. [CrossRef]

61. Jiang, Z.; Sun, L.; Yang, Q.; Yin, B.; Ke, H.; Han, J.; Wei, Q.; Xie, G.; Chen, S. Excess axial electrostatic repulsion as a criterion for pentagonal bipyramidal DyIII single-ion magnets with high Ueff and TB. J. Mater. Chem. C 2018, 6, 4273-4280. [CrossRef]

62. Gai, Y.-L.; Xiong, K.-C.; Chen, L.; Bu, Y.; Li, X.-J.; Jiang, F.-L.; Hong, M.-C. Visible and NIR Photoluminescence Properties of a Series of Novel Lanthanide-Organic Coordination Polymers Based on Hydroxyquinoline-Carboxylate Ligands. Inorg. Chem. 2012, 51, 13128-13137. [CrossRef] [PubMed]

63. Cañadillas-Delgado, L.; Fabelo, O.; Cano, J.; Pasán, J.; Delgado, F.S.; Lloret, F.; Julve, M.; Ruiz-Pérez, C. Dinuclear and twoand three-dimensional gadolinium(III) complexes with mono- and dicarboxylate ligands: Synthesis, structure and magnetic properties. CrystEngComm 2009, 11, 2131-2142. [CrossRef]

64. Beeby, A.; Clarkson, I.M.; Dickins, R.S.; Faulkner, S.; Parker, D.; Royle, L.; de Sousa, A.S.; Williams, J.A.G.; Woods, M. Nonradiative deactivation of the excited states of europium, terbium and ytterbium complexes by proximate energy-matched $\mathrm{OH}$, $\mathrm{NH}$ and $\mathrm{CH}$ oscillators: An improved luminescence method for establishing solution hydration states. J. Chem. Soc. Perkin Trans. 1999, 2, 493-504. [CrossRef]

65. Zaitoun, M.A.; Al-Tarawneh, S. Effect of varying lanthanide local coordination sphere on luminescence properties illustrated by selected inorganic and organic rare earth complexes synthesized in sol-gel host glasses. J. Lumin. 2011, 131, 1795-1801. [CrossRef]

66. Wang, Q.; Yan, X.; Zhang, H.; Liu, W.; Tang, Y.; Tan, M. Crystal structures and luminescent properties of lanthanide nitrate coordination polymers with structurally related amide type bridging podands. J. Solid State Chem. 2011, 184, 164-170. [CrossRef]

67. Bünzli, J.-C.G. On the design of highly luminescent lanthanide complexes. Coord. Chem. Rev. 2015, 293-294, 19-47. [CrossRef]

68. Aebischer, A.; Gumy, F.; Bünzli, J.-C.G. Intrinsic quantum yields and radiative lifetimes of lanthanide tris(dipicolinates). Phys. Chem. Chem. Phys. 2009, 11, 1346-1353. [CrossRef] [PubMed]

69. Latva, M.; Takalo, H.; Mukkala, V.-M.; Matachescu, C.; Rodríguez-Ubis, J.C.; Kankare, J. Correlation between the lowest triplet state energy level of the ligand and lanthanide(III) luminescence quantum yield. J. Lumin. 1997, 75, 149-169. [CrossRef]

70. Weber, M.J. Radiative and Multiphonon Relaxation of Rare-Earth Ions in $\mathrm{Y}_{2} \mathrm{O}_{3}$. Phys. Rev. 1968, 171, 283-291. [CrossRef]

71. Gonçalves e Silva, F.R.; Malta, O.L.; Reinhard, C.; Güdel, H.-U.; Piguet, C.; Moser, J.E.; Bünzli, J.-C.G. Visible and Near-Infrared Luminescence of Lanthanide-Containing Dimetallic Triple-Stranded Helicates: Energy Transfer Mechanisms in the SmIII and YbIII Molecular Edifices. J. Phys. Chem. A 2002, 106, 1670-1677. [CrossRef]

72. Werts, M.H.V.; Jukes, R.T.F.; Verhoeven, J.W. The emission spectrum and the radiative lifetime of Eu3+ in luminescent lanthanide complexes. Phys. Chem. Chem. Phys. 2002, 4, 1542-1548. [CrossRef]

73. Zhang, K.; Lu, Z.-Y.; Feng, C.-C.; Yang, Z.-R.; Nie, P.-P.; Chen, T.-T.; Zhang, L.-F.; Ma, S.; Shen, Y.-J.; Lin, M.-L. Series of Highly Luminescent Macrocyclic Sm(III) Complexes: Functional Group Modifications Together with Luminescence Performances in Solid-State, Solution, and Doped Poly(methylmethacrylate) Film. ACS Omega 2019, 4, 18334-18341. [CrossRef] [PubMed]

74. Yuan, B.; Wang, F.; Tao, J.; Li, M.; Yang, X. Self-assembly of one visible and NIR luminescent Sm(III) coordination polymer with flexible Schiff base ligand. Inorganica Chim. Acta 2019, 490, 24-28. [CrossRef]

75. Hunt, R.R.; McOmie, J.F.W.; Sayer, E.R. 109. Pyrimidines. Part X. Pyrimidine, 4: 6-dimethylpyrimidine, and their 1-oxides. J. Chem. Soc. 1959, 525-530. [CrossRef]

76. CrysAlisPRO; Version 1.171.40.53; Oxford Diffraction/Agilent Technologies UK Ltd.: Yarnton, UK, 2019.

77. Sheldrick, G.M. A short history of SHELX. Acta Cryst. 2008, 64, 112-122. [CrossRef]

78. Sheldrick, G.M. Crystal structure refinement with SHELXL. Acta Cryst. 2014, 71, 3-8.

79. Farrugia, L.J. WinGX and ORTEP for Windows: An update. J. Appl. Crystallogr. 2012, 45, 849-854. [CrossRef] 
80. Rodríguez-Carvajal, J. FULLPROF 2000, Version 2.5d; Laboratoire Léon Brillouin (CEA-CNRS), Centre d'Études deSaclay, Gif sur Yvette Cedex: Grenoble, France, 2003.

81. Earnshaw, A. Introduction to Magnetochemistry; Academic Press: London, UK, 1968.

82. Ruiz, E.; Cano, J.; Alvarez, S.; Alemany, P. Broken symmetry approach to calculation of exchange coupling constants for homobinuclear and heterobinuclear transition metal complexes. J. Comput. Chem. 1999, 20, 1391-1400. [CrossRef]

83. Frisch, M.J.; Trucks, G.W.; Schlegel, H.B.; Scuseria, G.E.; Robb, M.A.; Cheeseman, J.R.; Scalmani, G.; Barone, V.; Petersson, G.A.; Nakatsuji, H.; et al. Gaussian 16, Revision C.01; Gaussian, Inc.: Wallingford, UK, 2016.

84. Dennington, R.; Keith, T.; Millam, J. GaussView, Version 5; Semichem Inc.: Shawnee Mission, KS, USA, 2009.

85. Davies, D.L.; Lelj, F.; Lowe, M.P.; Ryder, K.S.; Singh, K.; Singh, S. Pyridine imines as ligands in luminescent iridium complexes. Dalt. Trans. 2014, 43, 4026-4039. [CrossRef] 